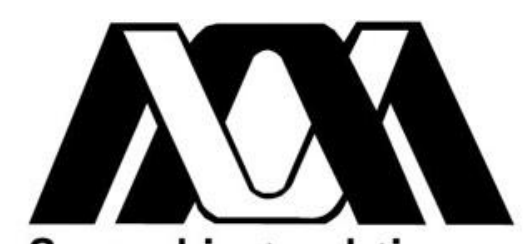

Casa abierta al tiempo

UNIVERSIDAD AUTÓNOMA METROPOLITANA

UNIDAD IZTAPALAPA

DIVISIÓN DE CIENCIAS BIOLÓGICAS Y DE LA SALUD

POSGRADO EN BIOLOGÍA EXPERIMENTAL

\title{
EFECTO DEL ESTRÉS PRENATAL EN EL APRENDIZAJE Y MEMORIA ESPACIAL EN LA RATA
}

\author{
TESIS \\ QUE PARA OBTENER EL GRADO DE MAESTRA EN \\ BIOLOGÍA EXPERIMENTAL \\ PRESENTA \\ B. E. MARÍA DE LOS ANGELES GUERRERO AGUILERA \\ DIRECTORA DE TESIS
}

DRA. MARÍA DEL SOCORRO IMELDA RETANA MÁRQUEZ

ASESORAS

DRA. SONIA GALVÁN ARZATE

DRA. MARÍA DEL CARMEN RUBIO OSORNIO 


\section{COMITÉ TUTORIAL}

\section{DIRECTORA}

\section{DRA. MARÍA DEL SOCORRO IMELDA RETANA MÁRQUEZ}

Departamento de Biología de la Reproducción

Área de Biología Conductual y Reproductiva

Universidad Autónoma Metropolitana Unidad Iztapalapa

ASESORA
Dra. Sonia Galván Arzate
Departamento de Neuroquímica
Instituto Nacional de Neurología y Neurocirugía
"Manuel Velasco Suárez"
ASESORA
Dra. María del Carmen Rubio Osornio
Departamento de Neurofisiología
Instituto Nacional de Neurología y Neurocirugía
"Manuel Velasco Suárez"


Este trabajo se realizó en el Departamento de Biología de la Reproducción, en la Universidad Autónoma Metropolitana Unidad Iztapalapa bajo la dirección y asesoría de la doctora María del Socorro Imelda Retana Márquez, la doctora Sonia Galván Arzate y la doctora María del Carmen Rubio Osornio.

El Programa de Maestría en Biología Experimental de la Universidad Autónoma Metropolitana pertenece al programa Nacional de Posgrados de Excelencia del CONACyTn(PNPC) registro 001481 y cuenta con apoyo del mismo Consejo, clave DAFCyT 2003IMPTNNN0020.

Para la realización de los estudios de maestría la alumna María de los Ángeles Guerrero Aguilera contó con el apoyo de beca CONACyT mediante el número de registro de la beca 224664/CVU:267992 


\section{Miembros del Jurado}

Los miembros del jurado fueron designados por la Comisión de Posgrado de la

División de Ciencias Biológicas y de la Salud, de la Universidad Autónoma Metropolitana Unidad Iztapalapa, los abajo firmantes aprobaron la tesis titulada:

\section{EFECTO DEL ESTRÉS PRENATAL EN EL APRENDIZAJE Y MEMORIA ESPACIAL EN LA RATA}

Que presentó

B. E. María de los Ángeles Guerrero Aguilera

El día 20 de julio del 2012

Dra. Leonor Rodríguez Cruz

Universidad Autónoma Metropolitana Iztapalapa

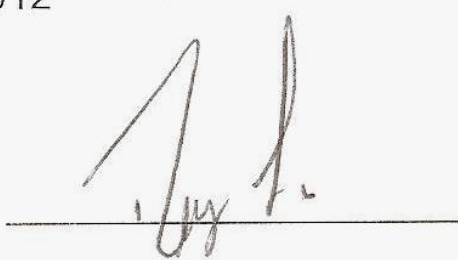

(Presidenta)

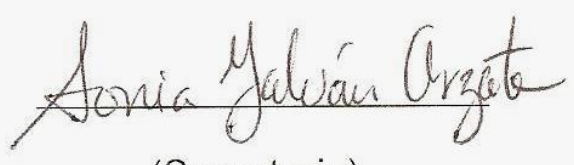

(Secretaria)

Instituto Nacional de Neurología y Neurocirugia "Manuel Velasco Suárez"

Dra. María del Carmen Rubio Osornio

Instituto Nacional de Neurología y Neurocirugía

"Manuel Velasco Suárez"

Dra. Wendy Portillo Martínez

Universidad Nacional Autónoma de México

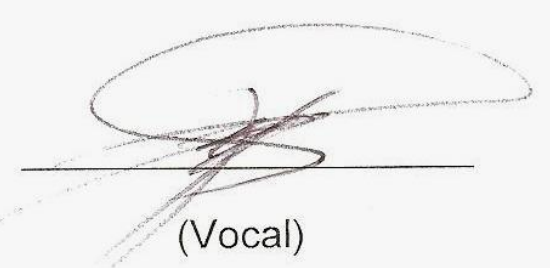

(Vocal)
(Vocal) 


\section{Resumen}

Se ha demostrado que el estrés prenatal por inmovilización causa deficiencias en el aprendizaje. Estas deficiencias parecen ser debidas a la exposición del feto a los glucocorticoides maternos durante el estrés. Se ha reportado además que la intensidad del estresor determina la cantidad de glucocorticoides liberados durante el estrés. Por otro lado, se ha descrito que los animales estresados prenatalmente, al ser manipulados durante la vida posnatal, enfrentan de manera exitosa las situaciones estresantes. En este trabajo se evaluó el aprendizaje y la memoria en ratas estresadas prenatalmente, así como en ratas de tres meses manipuladas en la vida posnatal.

Se utilizaron ratas hembra gestantes que fueron asignadas aleatoriamente a dos grupos: control (CTR) y estrés prenatal (EP). Las hembras CTR fueron mantenidas en sus cajas. Las hembras de EP fueron sometidas a 15 min de estrés (IMS) desde el día 15 hasta el 20 de gestación. Al nacimiento, se homogenizaron las camadas en cuanto a número de crías. Éstas fueron destetadas a los 21 días posteriores al nacimiento y asignadas aleatoriamente a 16 diferentes grupos: CTR y EP, hembras y machos de 1,2 y 3 meses de edad ( $2 \times 2 \times 3)$. Otros cuatro grupos (hembras y machos, CTR y EP) fueron manipulados de manera táctil (por 60s) durante el registro diario de peso corporal, desde el nacimiento hasta la edad de 3 meses. Todos los animales fueron sometidos al Laberinto Acuático de Morris (LAM), con un periodo de aprendizaje de 4 días consecutivos, con 4 sesiones por día, de 60s de duración como tiempo máximo. Dos días después del último día de aprendizaje se realizó una sola sesión de prueba en el LAM. Ocho días después

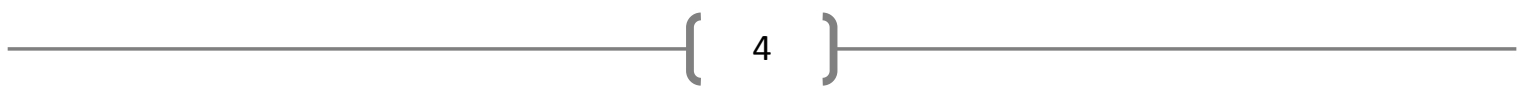


de la prueba de los 2 días se llevó a cabo una última sesión de prueba. Se registraron las latencias de llegada a la plataforma en cada sesión. Tres días después del último día de aprendizaje se realizó una sesión sin plataforma en el LAM y se registró el tiempo de permanencia dentro del cuadrante donde se colocó la plataforma durante la fase de aprendizaje, así como el número de cruces sobre la zona específica de la plataforma.

En casi todas las sesiones, tanto de aprendizaje como de memoria, se observó que las latencias de llegada de los animales EP, de todas las edades, fueron significativamente mayores que las de los grupos CTR. Se observó también que la manipulación postnatal revirtió los efectos del EP, ya que el desempeño de los animales EP fue igual al de los grupos CTR y CTR manipulado. Estos datos muestran que el estrés prenatal de alta intensidad disminuye la capacidad de aprendizaje y memoria en los individuos y que la manipulación postnatal es capaz de revertir este efecto. 


\section{ABREVIATURAS}

$\mathrm{ACTH}$

Corticotropina

ADHD ....... Trastorno por Déficit de Atención con Hiperactividad ANOVA Análisis de Varianza

CA 1 Cuerno de Ammon 1

CA 2 Cuerno de Ammon 2

CA 3 Cuerno de Ammon 3 CBG.........Transcortina o Globulina Unidora de Corticosteroides CNS Sistema Nervioso Central CORT Corticosteroides $\mathrm{CRH}$ Hormona Liberadora de Corticotropina CTR Control E.E.M Error Estándar de la Media EP .Estrés Prenatal GC Glucocorticoides

$\mathrm{HHA}$ Eje Hipotálamo-Hipófisis-Adrenal LAM Laberinto Acuático de Morris LTP Potenciación a Largo Plazo

LTD... Depresión a Largo Plazo

NE Noreste

NMDA N-metil-D-aspartato

NO Noroeste

POMC. Propiomelanocortina

SE Sureste

SO Suroeste $11 \beta-H S D 2$ $11 \beta$-hidroxiesteroide deshidrogenasa 


\section{Índice}

1. Introducción ............................................................. 10

1.1. Estrés ............................................................................. 10

1.1.1. Sistema nervioso autónomo ..................................... 12

1.1.2. Eje Hipotálamo-Hipófisis-Adrenal (HHA) ...................... 12

1.1.3. Los glucocorticoides ......................................... 13

1.1.4. Receptores de glucocorticoides .............................. 15

1.2. Neurobiología del aprendizaje y la memoria..................17

1.2.1. Fases de la memoria ................................................. 19

1.2.2. Consolidación de la memoria................................... 19

1.2.3. Memoria y plasticidad neural ...................................... 20

1.2.4. Papel del hipocampo en los procesos de aprendizaje y

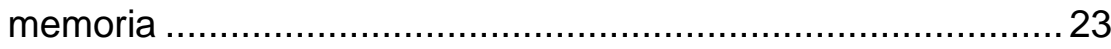

1.2.5. Aprendizaje y memoria espacial ............................... 24

1.2.6. Modelo del laberinto acuático de Morris como paradigma conductual de aprendizaje y memoria espacial en ratas...........27

1.3. Estrés, aprendizaje y memoria ........................................ 27

1.3.1. Estrés, aprendizaje y memoria hipocampal....................30 
1.3.2. Estrés y plasticidad en el hipocampo

1.3.2.1. Estrés y morfología dendrítica................................... 32

1.3.2.2. Estrés y neurogénesis ............................................. 33

1.4. Estrés durante la etapa prenatal .......................................3

1.4.1. Efectos del estrés prenatal en el feto ................................35

1.4.2. Efectos del estrés prenatal en la descendencia .............. 35

1.4.2.1. Efectos del estrés prenatal sobre el aprendizaje y la memoria......

1.5. Manipulación y estrés

39

1.5.1. Efectos de la manipulación en animales estresados prenatalmente 40

2. Justificación

3. Objetivos.................................................................. 42

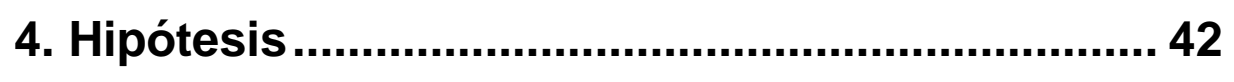

5. Metodología ......................................................... 43

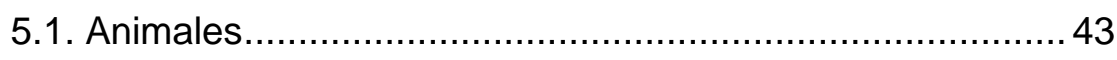

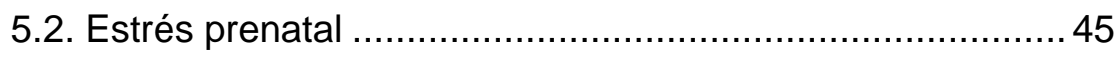


5.3. Manipulación y registro de peso corporal.

5.4. Paradigma conductual del laberinto acuático de Morris .....46 46

5.4.1. Instrumentación. 46

5.4.2. Fase de aprendizaje. 48

5.4.3. Fase de memoria de largo plazo 48

6. Análisis estadístico

7. Resultados.

7.2. Efectos del estrés prenatal por inmersión en agua fría sobre el aprendizaje y la memoria espacial

7.3. Efectos del estrés prenatal por inmersión en agua fría sobre el tiempo de permanencia en el cuadrante y el número de cruces

7.4. Efecto de la manipulación en los animales estresados prenatalmente por inmersión en agua fría sobre el aprendizaje

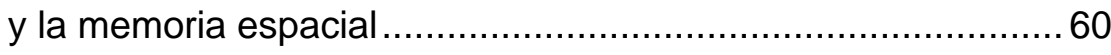

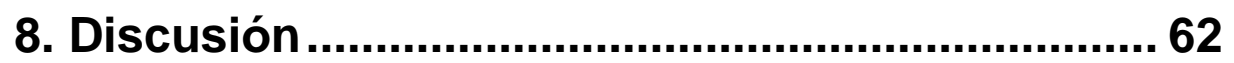

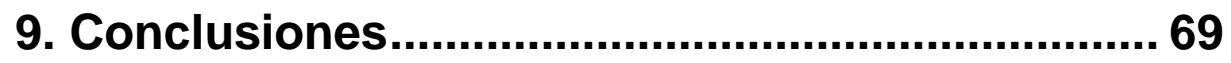




\section{Introducción}

\subsection{Estrés}

La vida existe gracias al mantenimiento de un equilibrio dinámico y complejo, conocido como homeostasis, mediante el cual el medio interno mantiene una condición estable. Sin embargo, los organismos también pueden mantener su estabilidad cambiando los niveles de referencia de los mecanismos homeostáticos, para así poder responder a eventos tales como los cambios circádicos o estacionales. Esto se conoce como alostasis, término que significa "alcanzar la estabilidad a través del cambio", y no pretende remplazar al término homeostasis (Sterling y Eyer, 1988, Mc Ewen, 1998). La alostasis por lo tanto permite que los organismos puedan hacer frente a las condiciones cambiantes del medio donde viven.

El estrés se ha definido como un estado de homeostasis alterada, en la que el organismo responde activando una serie de respuestas adaptativas centrales y periféricas (Johnson et al., 1992; Chrousos, 2007; Charmandari et al., 2005). Actualmente se considera que el estrés es una condición del organismo en la que las demandas ambientales, particularmente, situaciones que son impredecibles e incontrolables, exceden la capacidad reguladora del organismo. Fisiológicamente, el estrés se caracteriza por la ausencia de una respuesta anticipatoria 
(impredecible) así como por una baja recuperación después de la reacción neuroendocrina (incontrolable) (Koolhaas, et al, 2011).

La respuesta de estrés es dirigida por estructuras del SNC y por órganos periféricos. Los dos componentes principales del sistema de estrés son, el sistema Locus Coeruleus (sistema-LC), nervioso simpático (SNS)-médula adrenal y el eje Hipotálamo-Hipófisis-Adrenal (HHA). Ambos componentes interaccionan entre sí (Habib et al., 2001; Charmandari et al., 2005). El sistema de estrés recibe e integra diversas señales cognitivas, emocionales, neurosensoriales y periféricas que llegan a través de diferentes vías (Charmandari et al., 2005). La activación del sistema de estrés lleva a cambios conductuales (incremento en la vigilia, el estado de alerta, la cognición, el estado de vigilancia, en la atención enfocada, también se presenta euforia o disforia, incremento en la analgesia, supresión del apetito y del eje reproductivo) y físicos (redireccionamiento del oxigeno y nutrientes hacia el SNC y sitios estresados del cuerpo, incremento de la presión sanguínea, aumento en el ritmo cardiaco, incremento en la tasa respiratoria, incremento en la gluconeogénesis y lipolísis, inhibición del crecimiento, la reproducción, la digestión y de la estimulación en la motilidad colónica) que son marcadamente consistentes y en conjunto se definen como el síndrome de estrés. Estos cambios son adaptativos y de duración corta, y aumentan las probabilidades de supervivencia del individuo (Charmandari et al., 2005). 


\subsubsection{Sistema nervioso autónomo}

El sistema nervioso autónomo responde rápidamente a los estresores y controla un amplio rango de funciones cardiovasculares, respiratorias, endócrinas. Las neuronas del sistema Locus Coeruleus - sistema nervioso simpático (LCSNS) se localizan en el tallo cerebral (Nauta y Feirtag, 1979). La activación de este sistema por diversos estresores, causa la liberación de norepinefrina en estructuras cerebrales como la corteza cerebral, el sistema límbico, el hipotálamo y el tallo cerebral (Stanford y Salmon, 1993; Ma y Morilak, 2005), aumentando el estado de excitación, la vigilancia y la ansiedad. Al mismo tiempo, el sistema LCSNS estimula la secreción de epinefrina y norepinefrina desde la médula suprarrenal, así como la liberación de norepinefrina en las terminales nerviosas simpáticas. Lo cual causa el incremento en la frecuencia respiratoria y cardiaca, así como la movilización de glucosa hepática, todo ello para hacer frente a la demanda energética que impone la inmediata respuesta a los estresores (Tilders y Berkenbosh, 1986; Jezova et al., 1999).

\subsubsection{Eje hipotálamo-hipófisis-adrenal}

El eje HHA es un sistema que consta de tres estructuras: el hipotálamo, la hipófisis y las glándulas suprarrenales, mismas que a su vez liberan diferentes hormonas: la hormona liberadora de corticotropina $(\mathrm{CRH})$, la hormona adenocorticotropa (ACTH) y los glucocorticoides (GC), respectivamente. Durante la respuesta de estrés, la activación del eje HHA causa la liberación de $\mathrm{CRH}$. Éste es un péptido de 41 aminoácidos, sintetizado y liberado por las neuronas 
parvocelulares del núcleo paraventricular (PVN) del hipotálamo (Bloom et al., 1982). La CRH es liberada al sistema porta-hipofisiario, a través del cual es transportada hacia la hipófisis anterior. La CRH estimula en los corticotropos adenohipofisiarios la síntesis y secreción de $\mathrm{ACTH}$, a través de la unión a receptores específicos en esas células (Rivier y Vale, 1983; Aguilera et al., 2008). La ACTH liberada al torrente sanguíneo se une a receptores de alta afinidad, localizados en la membrana de las células de la corteza suprarrenal, donde estimula la síntesis y liberación de GC (de Kloet et al., 1998) (Figura 1).

\subsubsection{Glucocorticoides}

Los GC (cortisol en humanos y cortocosteroides en la rata) son hormonas de naturaleza esteroidea sintetizadas en la zona fasciculata y reticularis de la corteza suprarrenal (Ganong et al., 1974), a partir del colesterol y son liberados a la circulación en general. Una proporción alta, casi el 95\%, del cortisol o corticosterona que circula está unida a una alfa globulina llamada "transcortina" o globulina unidora de corticosteroides (CBG, por sus siglas en inglés) (Siiteri et al., 1982).

Los corticosteroides (CORT) en el cerebro de la rata actúan con otros componentes del sistema de la respuesta de estrés, de esta forma muestra dos modos de operación. El primero, donde los CORT mantienen la actividad basal del eje HHA y controla la sensibilidad del sistema de respuesta de estrés. Esta hormona coordina eventos de carácter circadiano, tales como el ciclo sueño-vigilia, 
la ingesta de alimento y está implicada en procesos que refuerzan la atención selectiva, integración de la información sensorial y en la elección de la respuesta

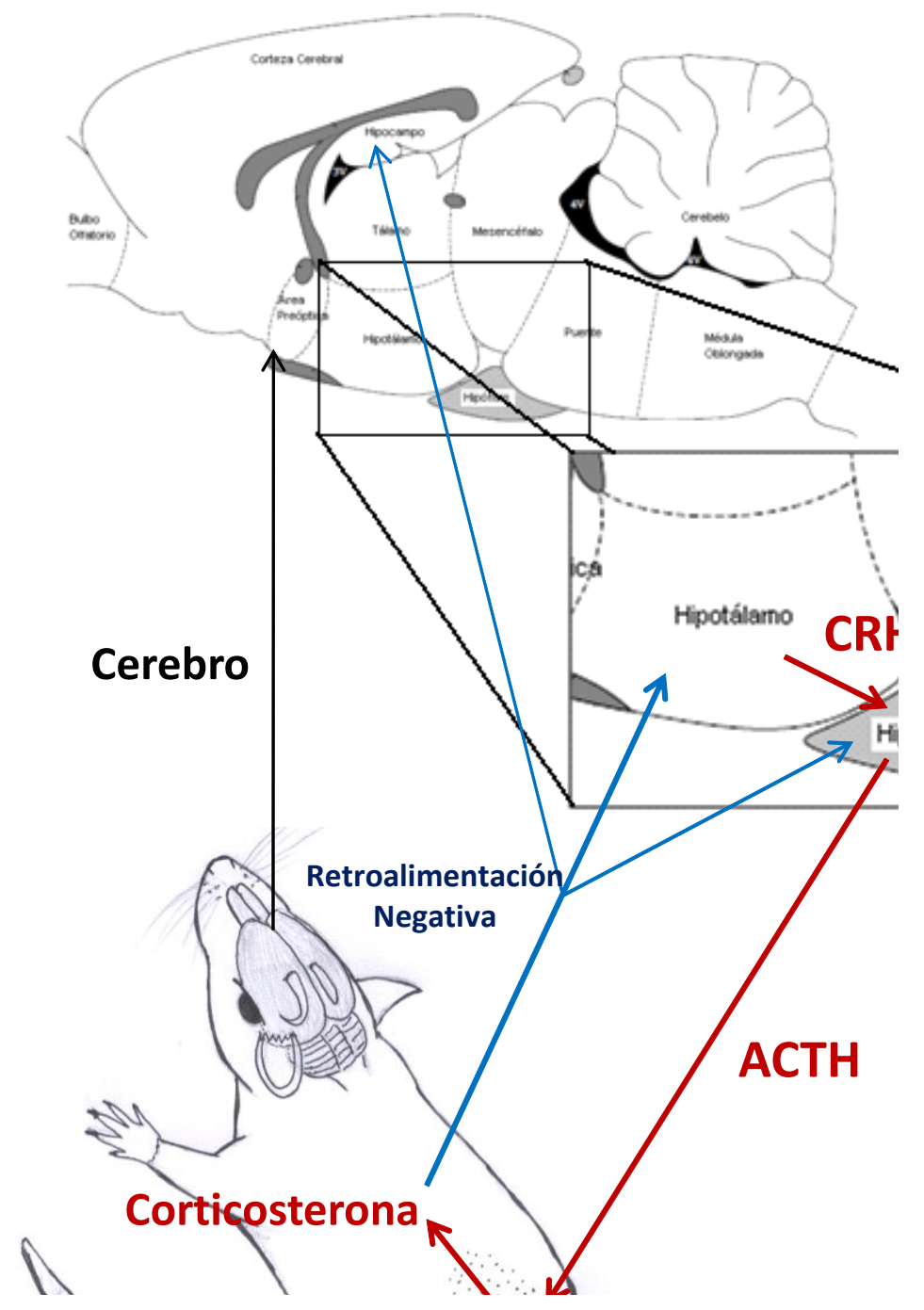

Figura 1.-Componentes del eje hipotálamo-hipófisis-adrenal en la rata y su posición en un corte sagital de rata (ACTH: Corticotropina, $\mathrm{CRH}$ : hormona liberadora de corticotropina) (Paxinos y Watson, 1998) 
conductual del organismo. En segundo modo, el sistema de retroalimentación de los CORT ayuda a terminar con la activación del eje HHA inducido por el estrés (de Kloet et al., 1998). Los efectos agudos de los CORT son euforogénicos, mientras que la elevación de forma crónica de los mismos produce depresión en un gran número de sujetos (Bohus et al., 1983).

A nivel periférico, los GC actúan en el hígado incrementando la síntesis de las enzimas que favorecen la gluconeogénesis (síntesis de glucosa a partir de sustratos no glucosídicos, como los aminoácidos, el lactato y el glicerol). Los GC también estimulan la movilización de ácidos grasos desde los adipositos. Estos efectos metabólicos de los GC aumentan la disponibilidad de energía, tanto para el cerebro como para los tejidos periféricos (Yates et al., 1980).

\subsubsection{Receptores de glucocorticoides}

Los receptores de GC se encuentran en todo el cerebro, y su acción sobre el sistema nervioso central (SNC) está mediada por dos tipos de receptores: receptores de GC tipo I y tipo II (Reul y de Kloet, 1985; Sapolsky et al., 1986, de Kloet et al., 1998). Los receptores tipo I se encuentran principalmente en las neuronas del hipocampo y del septum, pertenecientes al sistema límbico (Mc Ewen et al., 1968). Estos receptores participan en la modulación de la respuesta a los estímulos ambientales y emocionales (miedo, ansiedad, ingesta de alimento, etc.). Los receptores tipo I tienen una alta afinidad por la corticosterona (Reul y de Kloet 1985; Sapolsky et al., 1986). En el sistema límbico, estos receptores tienen alta especificidad por los agonistas de la corticosterona, mientras que los 
mineralocorticoides $(\mathrm{MC})$, como la aldosterona, parecen ser antagonistas competitivos (Moguilewsky y Raynaud, 1980; de Kloet et al., 1998). Los receptores tipo I que se encuentran en los órganos circunventriculares y funcionan como receptores a MC que responden a la aldosterona, y participan en la regulación homeostática del sodio, el control cardiovascular, además de controlar el apetito por la sal (Sapolsky et al., 1986).

Los receptores a GC tipo II están presentes en altas concentraciones en el hipotálamo, particularmente en las neuronas $\mathrm{CRH}$. Los receptores tipo II también se encuentran en áreas del cerebro que contienen proopiomelanocortina (POMC), como es el hipocampo, el septum lateral, la amígdala y el núcleo del tracto solitario (Mc Ewen et al., 1968). Los GC ejercen un circuito de retroalimentación negativa para terminar la liberación de la ACTH en respuesta al estrés y tienen efectos a largo plazo sobre el comportamiento adaptativo, presumiblemente por la vía de los receptores tipo II. Estos receptores tipo II disminuyen con la edad, pero no son afectados por la ACTH per se (Rigter et al., 1984; Sapolsky et al., 1983 a, b, 1986). La reducción de los receptores tipo II está asociada con la disminución de la acción de retroalimentación negativa de los GC, que pueden resultar en la elevación persistente de los niveles de GC en el plasma por efecto del estrés (Sapolsky 1985; Sapolsky y Pulsinelli 1985; Sapolsky et al., 1986).

El eje HHA es regulado por un mecanismo de retroalimentación negativa, la que consta de tres niveles: el hipocampo (Jacobson y Sapolsky, 1991) el núcleo para ventricular del hipotálamo y la adenohipófisis, siendo la actividad del eje HHA inhibida por los propios GC, a través de su unión a ambos tipos de receptores 
(Sapolsky et al., 1984, 1986). Los receptores de GC se localizan principalmente en el citosol y el núcleo de las neuronas y de los corticotropos, aunque también se localizan en la membrana plasmática de estas células (de Kloet, 1985)

Los GC ejercen retroalimentación negativa, suprimiendo en la hipófisis la secreción de ACTH y, en el hipotálamo, la secreción de $\mathrm{CRH}$, a través de receptores tipo II (Keller-Wood y Dallman, 1984). Estos mecanismos permiten al organismo mantener estables los niveles circulantes de GC.

Durante el estrés, la ocupación de los receptores tipo I cambia mínimamente, mientras que la ocupación de los receptores tipo II aumenta considerablemente (Reul et al., 1985), lo que permite al eje HHA disminuir su actividad en respuesta al estrés.

\subsection{Neurobiología del aprendizaje y la memoria}

El aprendizaje es un proceso continuo por el cual los organismos modifican su conducta. Este proceso, en el que intervienen factores internos y externos, consiste en la adquisición de conocimientos que permiten al individuo adaptarse mejor al medio que lo rodea (Morgado, 2005). La memoria es la función cognitiva que posibilita a un sujeto registrar, conservar y recuperar información o experiencias (ideas, imágenes, acontecimientos, sentimientos, etc.), es decir, mantiene los conocimientos adquiridos para que puedan ser recordados posteriormente (Klauer et al., 2000). En consecuencia, el aprendizaje y la memoria son procesos interrelacionados ya que sin aprendizaje no hay memoria (Morgado, 2005). 
Para entender lo anterior, es necesario considerar la plasticidad sináptica, que es la capacidad de las neuronas de modificar sus sinapsis (remplazándolas, disminuyéndolas o aumentándolas) en respuesta a determinados estímulos ambientales (Hebb, 1949; Hebb, 1976; Neves et al., 2008; Johansen et al., 2011). Estos mecanismos se encuentran implicados en las funciones cognitivas (aprendizaje y memoria), que dan como resultado cambios en el patrón de conectividad sináptica (Wood et al., 2001). Por lo anterior, se puede decir que los recuerdos se almacenan gracias a los cambios en la plasticidad sináptica (Fletcher et al., 1996). Una parte importante en la adquisición de la información es su carga emocional y la experiencia previa con la que cuente el individuo, los cuales determinarán la intensidad con la que la información es adquirida y consolidada a largo plazo (McGaugh y Cahill, 1997; Cahill et al., 2001).

El estudio del aprendizaje es crucial para entender la conducta normal y anormal en los humanos y los animales. Las técnicas conductuales basadas en el aprendizaje son ampliamente utilizadas en la investigación neurobiológica y clínica para evaluar alteraciones en el funcionamiento cerebral, así como los efectos de diversos fármacos o drogas. El aprendizaje se evalúa proporcionando a un sujeto experiencias de aprendizaje de manera repetida, observando los cambios progresivos en el desempeño. Esto da como resultado una curva de adquisición que evalúa la forma en que mejora el desempeño, en función del número de repeticiones y el tiempo. (Kupfermann, 1991).

El aprendizaje puede ser no asociativo o asociativo. El aprendizaje no asociativo produce un cambio en la conducta como resultados de la experiencia 
repetida a un único estímulo. Este procedimiento le permite al sujeto aprender acerca de las propiedades del estímulo. Existen dos tipos de aprendizaje no asociativo: la habituación (disminución de la respuesta conductual a un estímulo repetido, no nocivo) y la sensibilización (aumento de la respuesta a un estímulo repetido, nocivo o peligroso). En el aprendizaje asociativo se asocian dos o más estímulos relacionados (condicionamiento clásico) (Kupfermann, 1991).

\subsubsection{Fases de la memoria}

Lo que se aprende es retenido o almacenado en el cerebro y a esto se le denomina memoria. La formación de la memoria incluye dos estadios: la memoria a corto plazo y la memoria a largo plazo. La memoria a corto plazo se refiere a la entrada de información al cerebro, misma que persiste por unos cuantos segundos o minutos. Este tipo de memoria se basa en respuestas eléctricas o moleculares efímeras en las redes neurales implicadas (Morgado, 2005). Si la experiencia aprendida se repite, la maquinaria celular se activa, ocasionando que los cambios anteriormente mencionados continúen y cambien la morfología neuronal de manera permanente (Engert y Bonhoeffer, 1999), incrementándose tanto el número de receptores, la cantidad de neurotransmisor liberado y el número de contactos sinápticos. A este fenómeno se le conoce como memoria a largo plazo.

\subsubsection{Consolidación de la memoria}

La consolidación de la memoria hace referencia a los procesos neurobiológicos que se producen desde el momento en que se inicia el aprendizaje hasta que la información es almacenada (Cahill y McGaugh, 1996; 
Eichenbaum, 1997); pero si se interfiere la actividad cerebral inmediatamente después de una experiencia de aprendizaje, esta experiencia no quedará representada en el cerebro, es decir, se producirá amnesia retrógada (PradoAlcalá y Quirarte, 2007). Los GC (Castellano y Pluglisi-Allegra, 1983), los opiodes endógenos como son la $\beta$-endorfina y encefalina provocan un deterioro en la formación de la memoria (Zager y Black, 1985). Mientras que la epinefrina y la norepinefrina incrementan la consolidación de la memoria (Croiset et al., 2000) y la serotonina pueden modular la formación de la memoria después del aprendizaje (Kruglikov et al., 1991). La serotonina facilita, de manera presináptica, la liberación de otros neurotransmisores en el aprendizaje por sensibilización (Kandel, 1991).

\subsubsection{Memoria y plasticidad neural}

En 1949, Hebb propuso que, los cambios en las estructuras sinápticas, determinan la fuerza con la que se almacena la información a largo plazo; estos cambios de las estructuras sinápticas son consecuencia de una continua estimulación. Dicha estimulación es conocida como potenciación a largo plazo (LTP por sus siglas en inglés).

La LTP requiere de la activación del receptor y la despolarización de la neurona postsináptica. Los dos eventos son inducidos por una fuerte estimulación de alta frecuencia de las fibras presinápticas. El glutamato liberado de las terminales presinápticas por acción de la estimulación continua, actúa sobre varios tipos de receptores: los ionotrópicos NMDA (N-metil-D-aspartato), AMPA (ácido $\alpha$ amino-3hidroxi-5-metil-4-isoxazolpropiónico) y kainato. La activación de los 
receptores NMDA permite la entrada de $\mathrm{Ca}^{2+}$ a través de los canales iónicos específicos, y permite un cambio persistente en la expresión de receptores postsinápticos (AMPA), El aumento del $\mathrm{Ca}^{2+}$ en la parte dendrítica, activa a cinasas dependientes de $\mathrm{Ca}^{2+}$ como la proteína-cinasa dependiente de $\mathrm{Ca}^{2+}$, calmodulina y la proteína-cinasa C. Una isoforma de la proteína quinasa C, queda persistentemente activa. Así queda inducido el estado de LTP: por despolarización, por entrada de $\mathrm{Ca}^{2+}$ y también la por activación por $\mathrm{Ca}^{2+}$ de la formación de segundos mensajeros retrógrados (ácido gamma aminobutírico GABA, oxido nítrico NO, factor neurotrófico derivado del cerebro, BNDF). los cuales son liberados por las neuronas postsinápticas. (Mc Donal et al., 2006; Rodríguez, 2003)(Figura 2).

La entrada de $\mathrm{Ca}^{2+}$ por la activación de los receptores NMDA activa a diferentes proteinas-cinasas que promueven cambios en el citoesqueleto, los que generan cambios en la morfología de la neurona y de esta forma, se crean nuevas regiones sinápticas (Bailey y Kandel, 1993). Por otro lado, los factores de transcripción regulados dentro del núcleo de la neurona postsináptica, producen la síntesis de ARNm orientado a transcribirse en nuevas proteínas que se destinan a estabilizar los cambios morfológicos producidos (Casadio et al., 1999; Martin et al., 1997). 
A TRANSMISIÓN SINÁPTICA NORMAL
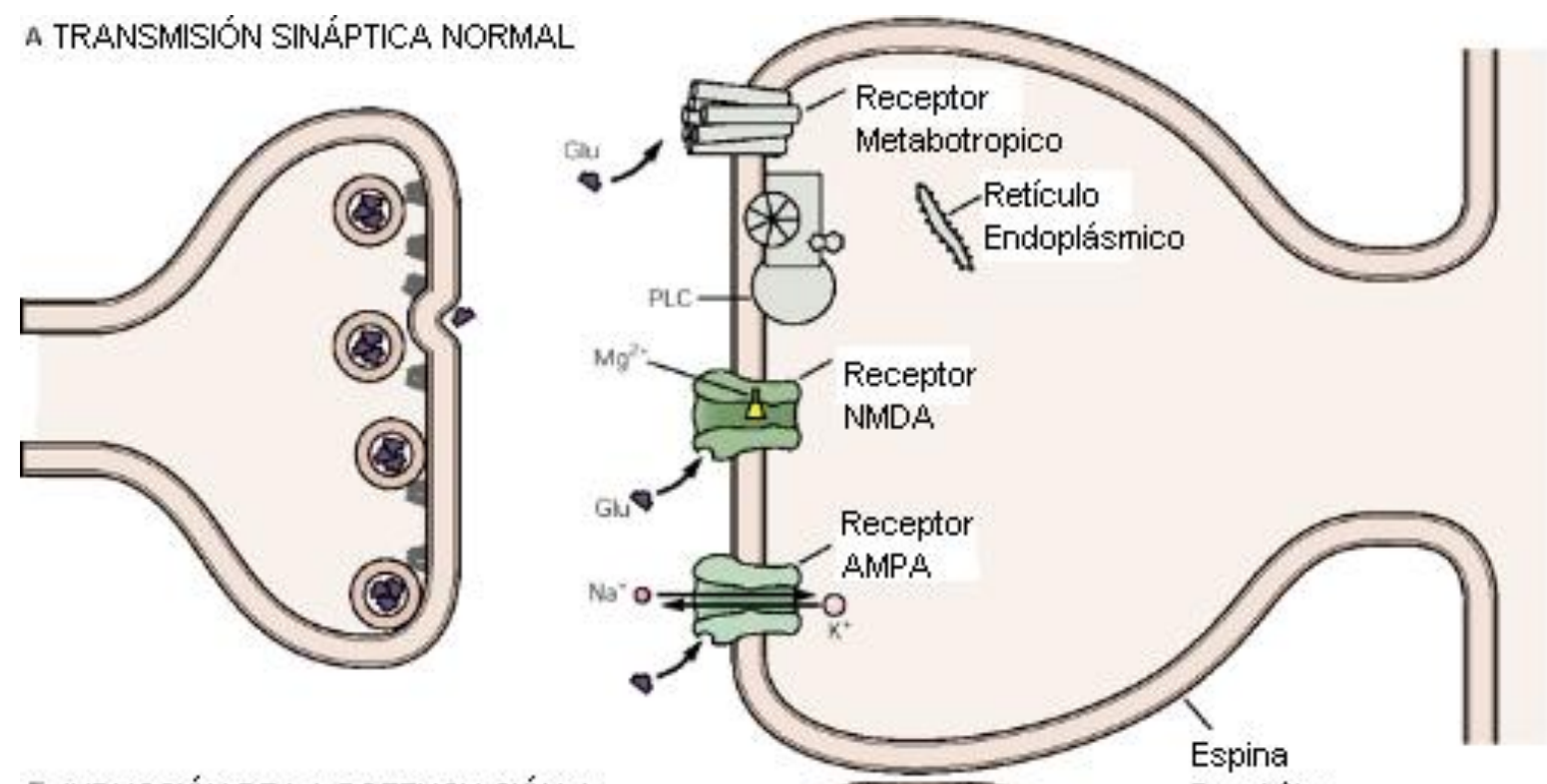

B INDUCCIÓN DE LA POTENCIACIÓN A LARGO PLAZO (LTP)
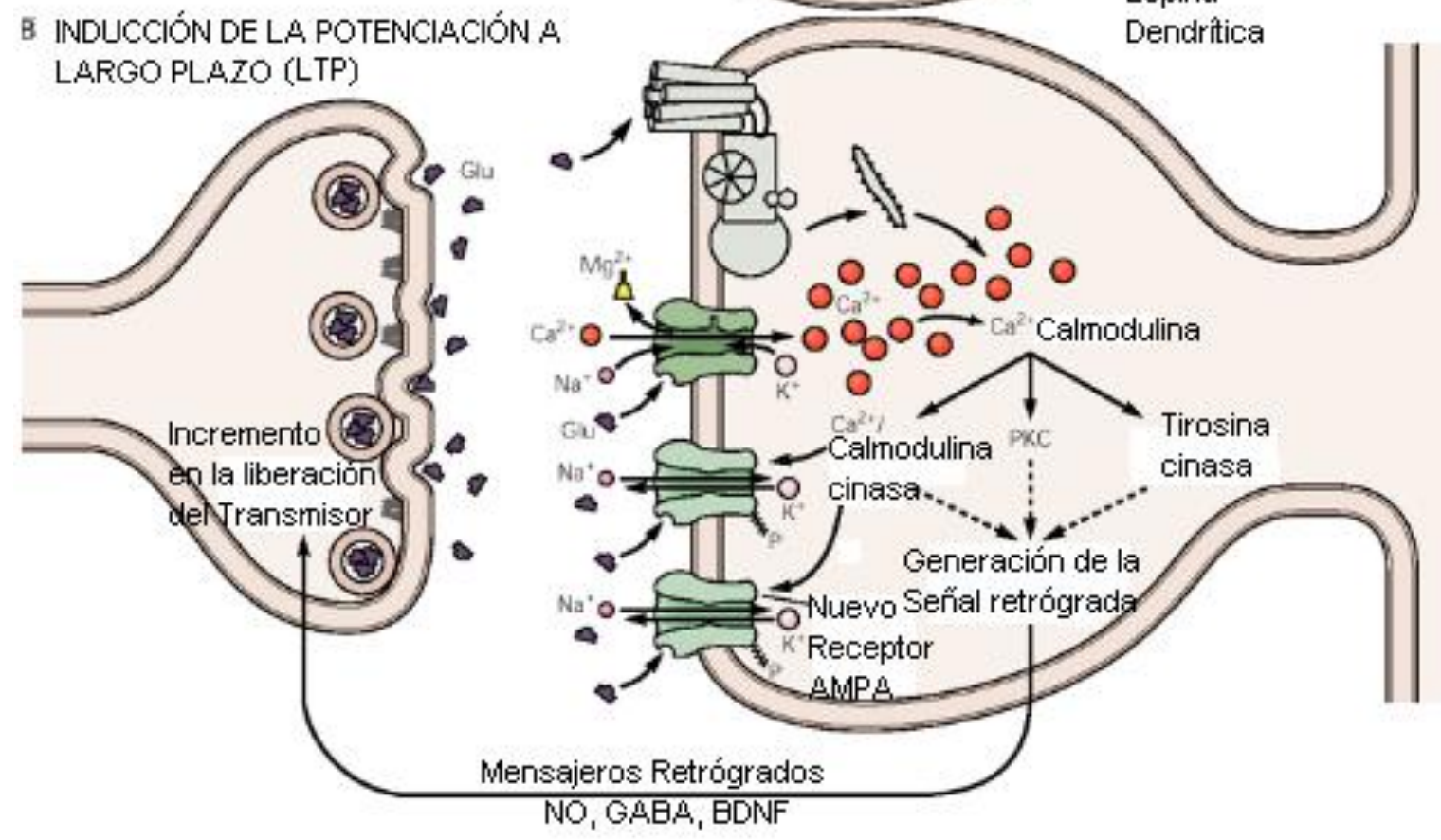

Figura 2.- Representación esquemática de la potenciación a largo plazo (LTP), La liberación de glutamato (Glu) activa los receptores NMDA permitiendo un incremento en la entrada de calcio y produce diversos cambios en la neurona postsináptica (Producción de nuevos receptores AMPA, creación de una señal retrograda que incrementa la liberación de glutamato de la neurona presináptica y cambios morfológicos en la neurona postsináptica) (NMDA: N-metil-Daspartato, AMPA: ácido a-amino-3-hidroxi-5-metil-4-isoxazolpropiónico, NO: oxido nítrico, GABA: ácido y-amino-butírico)(adaptado de www.slideshare.net/jorge_p/neuroplasticidad-1312515). 


\subsubsection{Papel del hipocampo en los procesos de aprendizaje y memoria}

El hipocampo, es una estructura bilateral del lóbulo temporal medial, con una importante conexión con la corteza entorrinal, tiene conexiones sinápticas con distintas áreas de la corteza. El hipocampo también tiene conexiones sinápticas con estructuras profundas a través del fórnix. Los cuerpos celulares y las proyecciones de las neuronas piramidales se alinean en una sola capa; formación que se conoce como Cuerno de Amón (CA), dividido en las regiones 1, 2 y 3. Las células granulares se alinean en el giro dentado (Figura 3). Se ha reportado que el hipocampo (área CA 3 principalmente) participa en la formación de la memoria declarativa (o explicita) en humanos (Scoville et al., 1957; Squire y Zola-Morgan, 1991; Gabrielli, 1998; Eichenbaum, 2000). En roedores, está implicada en la formación de la memoria de tipo espacial (o relacional). O’Keefe y Dostrovsky en 1971 descubrieron las "células de lugar" en el hipocampo, que se activan preferentemente cuando el roedor se encuentra en una localización espacial específica y sus potenciales de acción fueron monitoreados de manera extracelular en las regiones CA 1 y CA 3 (Fox y Ranck, 1957; Muller, 1996; Shen et al., 1997).

Por otro lado estudios en ratas, monos y humanos sugieren que, contrariamente al sistema hipocampal, los ganglios basales median un particular tipo de aprendizaje y memoria: el aprendizaje de estímulo-respuesta (S-R por sus siglas en inglés), y se basa en la ejecución de prueba y error (Packard y Mc Gaugh, 1992; Mc Donald y White, 1994). Existen evidencias de que el caudadoputamen (estriado dorsal) es necesario para la adquisición y la expresión de las 
asociaciones S-R y para el aprendizaje y memoria de ganancia-estancia, en el cual el animal repite una conducta que le otorga una recompensa. Esta conducta difiere a la de ganancia-escapatoria, implicada en la memoria explícita (memoria espacial) (Packard et al., 1989; Packard y Mc Gaugh 1992, 1996; Mc Donald y White, 1994). Estas situaciones solo son un ejemplo de lo que difieren los ganglios basales en su participación dentro del aprendizaje. Aunque en algunos estudios donde el roedor explícitamente mantiene asociaciones consientes (por ejemplo aprendizaje de lugar) el hipocampo tiene una participación importante en los inicios del aprendizaje explicito, en el que posteriormente el estriado tomara el control cuando la prueba pueda ser repetida al punto en la que el animal puede ejecutar la prueba sin un conocimiento explicito (Mc Donald y Withe, 1994; Packard y Mc Gaugh, 1996). Así aunque se presente un daño en el cuerpo estriado, el conocimiento puede estar parcialmente intacto, por que las estrategias basadas en el aprendizaje hipocampal pueden parcialmente compensar las deficiencias de los ganglios basales (Packard y Knowlton, 2002).

\subsubsection{Aprendizaje y memoria espacial}

Las ratas son excelentes corredoras, nadadoras, cavadoras y trepadoras, y mediante estas capacidades motoras encuentran su alimento y evitan la predación, por lo que su orientación dentro de su medio es primordial.

El aprendizaje y memoria espacial es la capacidad que tiene el animal de adquirir y retener asociaciones de las características del ambiente, lo que le permite desenvolverse en el espacio (Vicens et al., 2003). De esta forma la 
memoria espacial consiste en múltiples mecanismos que se encargan de codificar, almacenar y recuperar información de rutas, configuraciones y localizaciones espaciales (Kessels et al., 2001).

Los roedores pueden adoptar cuatro formas principales de navegación para la resolución de tareas espaciales: orientación, guía, cartográfica y de integración de ruta (Santín et al., 2000). En el aprendizaje de orientación los animales basan su búsqueda en movimientos aprendidos durante la ejecución de la tarea; en el aprendizaje de guía aprenden asociaciones entre estímulos señal y la meta. Estas dos formas de navegación se explican mediante paradigmas asociativos de condicionamiento. El aprendizaje cartográfico implica el uso de señales distales con las que los roedores se forman una representación del entorno (mapa cognitivo) mediante el que localizan la meta. Y la última forma de navegación es la de integración de ruta, que consiste en un proceso de actualización de la información cuando las pistas ambientales no ofrecen la suficiente, mediante un sistema interno de referencia basado en el lugar de salida antes de iniciar la navegación, para lo que el animal utiliza principalmente pistas cinestésicas y señales vestibulares (Santín et al., 2000). En el laberinto acuático las ratas tienden a aproximarse a la plataforma sumergida desde una dirección conocida, lo que sugiere la utilización de representaciones específicas para reconocer su localización, lo que implica establecer relaciones entre distintos estímulos (Wang y Spelke, 2002).

El laberinto acuático (LAM) es uno de los modelos más empleados en el estudio de la memoria espacial en la rata. En este laberinto los animales tienen 
que nadar en una piscina circular hasta localizar una plataforma oculta. Los animales se guían por claves extra laberinto que se localizan en torno al mismo; se requiere de pocos ensayos para aprender la prueba (Vicens et al., 2003). Los ensayos pueden distribuirse en distintas sesiones de aprendizaje y en días consecutivos. Con forme se repiten las pruebas, el tiempo empleado para encontrar la plataforma (llamado latencia de escape) disminuye, observándose una curva progresiva de aprendizaje, que se caracteriza por latencias progresivamente menores.

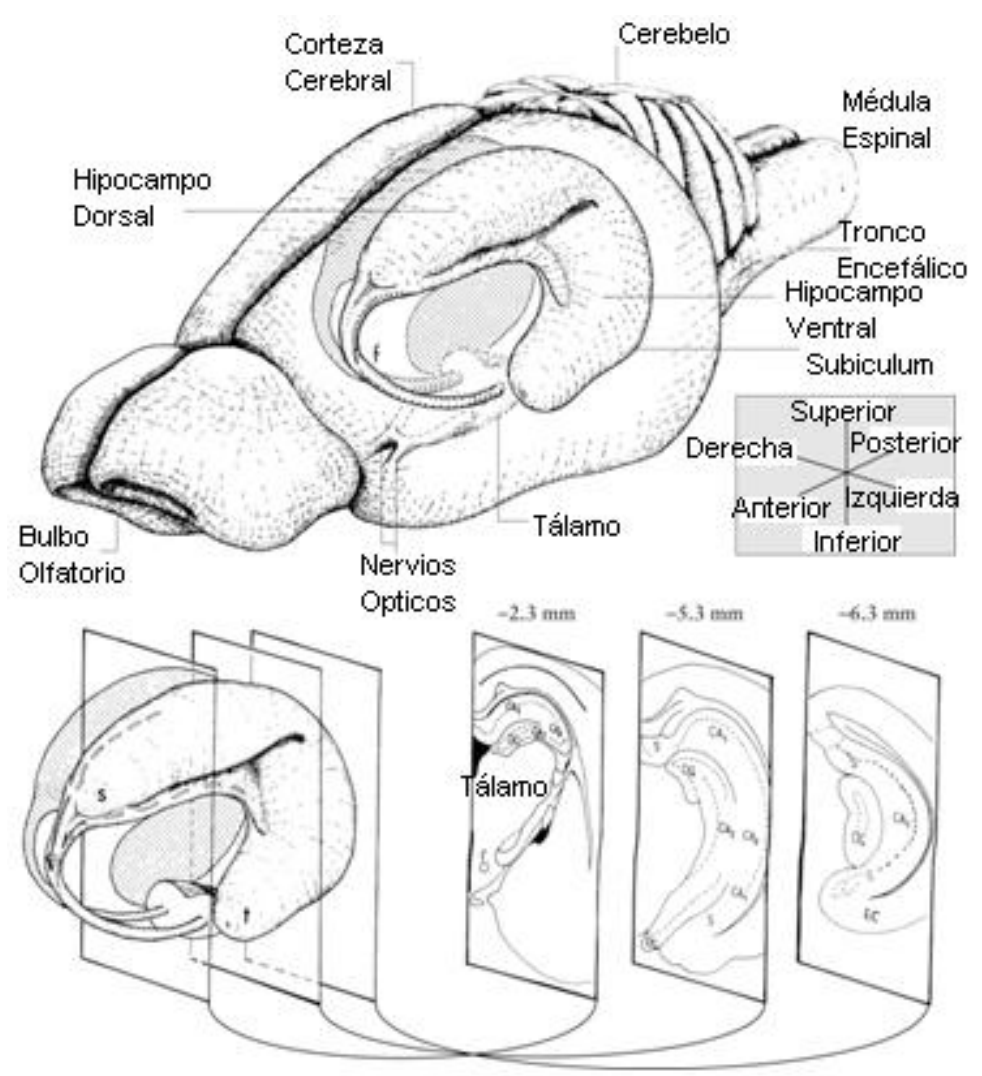

Figura 3.- Posición del hipocampo en el cerebro de la rata y de las áreas CA1, CA2 y CA3 en cortes coronales (Modificado de www.biomedcentral.com/1471-2202/6/36/figure/F3?highres=y). 


\subsubsection{Modelo del Laberinto Acuático de Morris como paradigma conductual de aprendizaje y memoria espacial en la rata}

En el LAM no se necesita la privación de agua o comida ni de la aplicación de una descarga eléctrica para motivar la conducta y se evita que los animales usen claves no espaciales (como los olores) para resolver la tarea. Asimismo, con esta prueba se pueden valorar los efectos de los fármacos sobre los procesos de aprendizaje y memoria de forma más efectiva que en otros laberintos de adquisición más lenta, como en el laberinto radial, en el que resulta más difícil

distinguir entre los efectos agudos y crónicos (Vicens et al., 2003). Además la confiabilidad de las pruebas en el LAM es adecuada, ya que, a diferencia de otras pruebas conductuales, las latencias de escape durante los entrenamientos no se modifica por cambios en la reubicación de los aparatos, en los protocolos de entrenamiento, en las condiciones de alojamiento, o por la edad de los animales (Crabbe et al., 1999).

\subsection{Estrés, aprendizaje y memoria}

Diversos autores coinciden en que el estrés es un potente modulador del aprendizaje y la memoria (Mc Ewen et al., 1968; de Kloet et al., 1999; Lupien y Lepage, 2001; Diamond et al., 2005; Joël et al., 2006; Shors, 2006), ya que se considera, deteriora las funciones cognitivas. Sin embargo, en otros estudios se ha observado que las funciones neurales y la cognición son facilitadas por el estrés (de Kloet et al., 1999, Fujioka et al., 2001; Fujioka et al., 2006), lo que sugiere que la interacción entre las funciones cognitivas y el estrés son complejas. Estas 
diferencias en los efectos del estrés pueden ser explicadas por las características físicas del estresor, tales como su "intensidad" y/o su duración (Cordero et al., 1998), así como de las respuestas neuroendócrinas durante el estrés (Baldi y Bucherelli, 2005; Conrad, 2005; Joëls, 2006).

La forma en que se afectan los procesos cognitivos durante el estrés depende de varios factores que actúan sobre el organismo:

1-.Intensidad del estresor: Niveles de hormonas en el organismo durante y después de la situación estresante. Los niveles elevados de las hormonas (CORT, epinefrina y norepinefrina) liberadas durante el estrés inducen un efecto en forma de $U$ invertida sobre el aprendizaje, memoria y plasticidad; se refiere al hecho de que los niveles hormonales presentes que aumentan debido al estrés ocasionan que las funciones cognitivas (el aprendizaje y la memoria) se deterioren (Baldi y Bucherelli, 2005; Conrad, 2005; Joëls, 2006).

2.-Duración del estrés: Agudo (una sola exposición) o crónico (exposiciones repetidas. Los efectos de la duración del estrés pueden ser evaluados a nivel cognitivo, pero también en función de las estructuras cerebrales involucradas en el aprendizaje y la memoria (Sandi y Loscertales, 1999; Pinnock y Herbert, 2001; Pecoraro et al., 2005; Joëls et al., 2006).

3.-Fase de la memoria en la que se presenta la situación estresante: Si se presenta durante la consolidación (principalmente se facilita) o durante la recuperación de la información (principalmente se deteriora) (Roozendaal, 2002 y 2003). 
4.-Carga psicológica: $\mathrm{Si}$ el estresor es incontrolable y/o impredecible (Mineka y Hendersen, 1985). Existe evidencia experimental de que las experiencias incontrolables en contraposición a las controlables, tienen un efecto nocivo sobre el procesamiento de la información (Maier y Watkins, 2005).

5.-Características individuales de cada organismo: Edad o sexo del individuo (Bowman et al., 2003; Shors, 2004).

6.-Contexto en el cual se presenta el estrés o bien las hormonas de estrés que son liberadas. Esto es: si la experiencia es considerada estresante o no (de Kloet et al., 1999; Joëls et al., 2006; Sandi, 1998).

Los efectos del estrés en la rata macho adulta se pueden explicar de acuerdo a los siguientes factores:

1.-La fuente del estrés: El estímulo estresante puede ser intrínseco, cuando es originado por la misma prueba cognitiva o extrínseco, cuando es originado por factores no relacionados con la prueba cognitiva, como son eventos del medio que la rodean y que pueden presentarse antes o después de la misma) (Sandi y Pinelo-Nava, 2007).

2.-La duración del estrés: Agudo o crónico. Esto es importante cuando se evalúan los mecanismos neurales mediante el cual el estrés afecta la cognición (Sandi y Pinelo-Nava, 2007).

3.-La intensidad del estresor: Los estresores pueden variar a lo largo de una amplia gama de intensidades: baja, media, alta y en ocasiones de muy alta 
intensidad. Por ejemplo: un estresor de baja intensidad es la exposición a una situación novedosa por otro lado un estresor de alta intensidad es una clara amenaza a la vida como la exposición a un depredador (Cordero et al., 1998; Joëls et al., 2006; Sandi y Pinelo-Nava, 2007).

4.-El estresor y las fases de la memoria (adquisición, consolidación y recuperación de la información): Dependiendo de la fase de la memoria en la que el evento estresante es experimentado. El estrés y los mediadores del estrés ejercen efectos opuestos: generalmente se facilita la consolidación (almacenamiento de la información en la memoria) y b) la recuperación generalmente se deteriora; de esta forma no se tiene un acceso eficiente a la información almacenada (Roozendaal, 2002 y 2003; de Kloet et al., 1999; Joëls et al., 2006).

5.-El tipo de aprendizaje: Es importante el tipo de proceso de aprendizaje que es evaluado (aprendizaje implícito/no declarativo, explícito/declarativo, no asociativo, etc.) (Nelson et al., 1992; Squire y Zola, 1996; Verfaellie y Keane, 1997; Eichenbaum, 1999; Moscovitch et al., 2006). Las ratas son usadas como modelos para los procesos de aprendizaje y memoria explícita.

\subsubsection{Estrés, aprendizaje y memoria hipocampal}

El hipocampo es una estructura cerebral implicada tanto en la memoria como en la regulación neuroendocrina de las hormonas del estrés. Así mismo, es

un blanco de las hormonas del estrés, teniendo una de las más altas concentraciones de receptores de CORT en el cerebro. Una función importante del 
hipocampo es la de participar en la finalización de la respuesta de estrés por medio de la retroalimentación negativa, mediada por los receptores de GC que inhiben al eje HHA (Sapolsky, 1992; McEwen y Sapolsky, 1995). Por otro lado, los niveles elevados de corticosterona en el hipocampo, afectan el metabolismo, la sobrevivencia, las funciones fisiológicas y la morfología de sus neuronas (Kim y Yoon, 1998; de Kloet et al., 1999; Mc Ewen, 2000; Mc Ewen y Sapolsky, 1995; Sapolsky, 1992); así como sus funciones relacionadas con el aprendizaje y la memoria (Lemaire et al., 2000; Hosseini-sharifabad y Hadinedoushan, 2007).

Diferentes estudios muestran que, el estrés y las hormonas del estrés deterioran la memoria dependiente del hipocampo, tanto en humanos como en animales (Sapolsky, 1992; de Kloet et al., 1999; McEwen, 2000; Diamond et al., 2001; Krischbaum et al., 1996; Diamond y Park 2000). Consistentemente con lo reportado en humanos, la exposición de ratas a estrés, o bien la administración de corticosterona (en dosis comparables a las que se presentan en la respuesta de estrés) causaron déficit en la memoria espacial acompañado de modificaciones en la estructura neuronal del hipocampo (disminución de las ramificaciones dendríticas de CA 1) (Luine et al., 1993; Diamond et al., 1999; Diamond et al., 1996; de Quervain et al., 1998).

\subsubsection{Estrés y plasticidad en el hipocampo}

Los efectos del estrés sobre la plasticidad hipocampal se han observado en paradigmas tales como la desesperanza aprendida. En este paradigma los animales expuestos al estresor (por ejemplo, inmovilización-choques eléctricos en 
la cola) no pueden escapar de la experiencia nociva, lo que provoca el aumento en la liberación de corticosterona que su vez ocasiona un aumento en la concentración de glutamato lo que permite la inducción de la LTD provocando el deterioro en el aprendizaje y la memoria. Por otro lado, las ratas que sí pueden ejecutar alguna conducta para terminar con la condición estresante (escape del lugar), muestran una LTP mayor que los animales que no pueden escapar del estresor (Maier y Seligman 1976; Shors et al., 1989). Se ha demostrado que otras formas de estrés psicológico (como la exposición a un depredador, condiciones inestables de alojamiento, inestabilidad social, etc.) disminuyen la LTP (Diamond y Park 2000; Xu et al., 1997; Diamond et al., 1994, 1990).

\subsubsection{Estrés y morfología dendrítica}

Otro aspecto importante de los efectos del estrés sobre el hipocampo, es el cambio en la morfología dendrítica de las neuronas. Se ha observado que la exposición diaria a estrés por inmovilización, o inyecciones de CORT por tres semanas, causa atrofia de las dendritas apicales en las neuronas piramidales de CA3 (McEwen, 2000). De esta misma forma, se han reportado cambios morfológicos en las células del giro dentado y CA1. En CA1 se observa retracción dendrítica en las células granulosas y en las neuronas en ratas adultas expuestas a estrés impredecible durante un mes (Sousa et al., 2000). La atrofia de las dendritas apicales en el hipocampo puede ser suprimida con drogas que reducen la neurotransmisión de aminoácidos excitatorios (aspartato y glutamato), o bien

que reducen los niveles extracelulares de 5-hidroxitriptamina $(5-\mathrm{HT})$ o la excitabilidad general, a través de la estimulación GABAérgica (Brown et al., 1999). 


\subsubsection{Estrés y neurogénesis}

La formación de nuevas células neuronales en el giro dentado adulto ha sido documentada en diferentes especies, incluyendo la rata, los titíes, los monos Rhesus, las musarañas arborícolas y el humano (Gould y Gross 2002; Charil et al., 2010; Lafenêtre et al., 2010; Brandt et al., 2010). Se ha documentado que este mecanismo está relacionado con los procesos de aprendizaje y memoria. Por ejemplo, bajo condiciones en las que se estimula aprendizaje explícito (en humanos) o espacial (en la rata) en el que interviene el hipocampo, el número de células granulares y su sobrevivencia se incrementa (Gould et al., 1999; Gould y Gross 2002).

El estrés o la administración experimental de GC inhiben la formación de células en el hipocampo. El estrés agudo afecta la proliferación de células granulares en la rata adulta, en musarañas arborícolas y en los titíes. En las musarañas arborícolas estresadas de manera crónica, se ha demostrado la disminución en el número de células granulares (Gould et al., 1997).

\subsection{Estrés durante la etapa prenatal}

Las situaciones estresantes experimentadas por la madre gestante pueden provocar alteraciones en el ambiente del feto y ocasionar deterioro en el desarrollo de la descendencia. En diferentes estudios se ha reportado que el estrés causado por la violencia psicológica, física y/o sexual durante la gestación en las mujeres mexicanas, tiene una prevalencia de entre el 9 y 34 por ciento (Castro et al., 2003; Valdez-Santiago y Sanin-Aguirre, 1996; Díaz-Olavarrieta et al., 2005) En 
consecuencia, estas mujeres tienen tres veces más complicaciones durante el parto y cuatro veces más probabilidades de que los recién nacidos presenten bajo peso (Valdez-Santiago y Sanin-Aguirre, 1996). En Estados Unidos se ha reportado que el 6 por ciento de las mujeres embarazadas están expuestas a estrés psicosocial severo y violencia doméstica durante sus gestaciones, lo que les ocasiona alteraciones tales como depresión y desórdenes de pánico (Woods et al., 2010).

En los humanos el estrés prenatal (EP) está ligado al incremento en la vulnerabilidad a desarrollar varios problemas psicosociales, mismos que se pueden observar tanto en la niñez como en la etapa adulta. Durante la niñez, el estrés prenatal (EP) está asociado con problemas de cognición, de conducta y de desarrollo cerebral (King y Laplante, 2005; King et al., 2009; Laplante et al., 2004, 2008; Talge et al., 2007), tales como el autismo (Beversdof et al., 2005; Kinney et al., 2008 a, b) y el trastorno por déficit de atención con hiperactividad (ADHD) (Grizenko et al., 2008; Li et al., 2010; Linnet et al., 2003; Mc Intosh et al.,1995; Rodríguez y Bohlin, 2005). En los adultos, el EP se ha asociado con depresión (Watson et al., 1999) y esquizofrenia (Huttenen y Niskanen, 1978; Kinney et al., 1999; Kinney, 2001; van Os y Selten, 1998) así como con hipertensión, diabetes tipo 2 y enfermedad isquémica cardiaca en ciertas etapas de la vida posnatal (Maccari y Morley-Fletcher, 2007). 


\subsubsection{Efectos del estrés prenatal en el feto}

La exposición al estrés durante la gestación, incrementa los niveles de CORT y catecolaminas maternos, los cuales llegan a la sangre del feto (Ward y Weisz 1984; Takahashi et al., 1998; Weinstock et al., 1988; Rohde et al., 1983). Así, los CORT maternos que normalmente son reducidos a su forma inactiva por la enzima placentaria $11 \beta$-hidroxiesteroide deshidrogenasa tipo dos (11ß-HSD2) pasan hacia el feto, debido que la actividad y la expresión de esta enzima placentaria se encuentran reducidas en las madres estresadas (Charil et al., 2010).

Por otro lado, la liberación de $\mathrm{CRH}$ de origen placentario se incrementa por el exceso de CORT maternos, lo que permite que, progresivamente los niveles de esta hormona aumenten en el plasma fetal y actúen sobre el cerebro del feto (Kastin y Akerstrom, 2002). Esta CRH puede entonces afectar la función y la integridad del hipocampo en desarrollo, debido a la activación de los receptores de $\mathrm{CRH}$ presentes en el hipocampo fetal (Sandman et al., 1999; Wadhwa et al., 2001).

\subsubsection{Efectos del estrés prenatal en la descendencia}

En los humanos, la exposición al estrés durante la gestación modifica el desarrollo cerebral de los neonatos, ocasionando alteraciones permanentes que incrementan la susceptibilidad de padecer desordenes cognitivos o psiquiátricos en la vida posnatal. Se ha observado que el estrés prenatal ocasiona retardo en el 
crecimiento fetal, bajo peso al nacer (Cliver et al., 1992) y retraso en el desarrollo motor (Huizink et al., 2003).

La exposición al estrés prenatal en ratas, trae como consecuencia el incremento de la respuesta del eje HHA ante situaciones estresantes durante la vida posnatal (Henry et al., 1994; Maccari et al., 1995; Vallée et al., 1997; MorleyFletcher et al., 2003a, b) de las cuales se recuperan lentamente (Fride et al., 1986; Maccari et al., 1995). Las ratas adultas de ambos sexos que han sido estresadas prenatalmente presentan mayor secreción de CORT al final del periodo de luz en comparación con las ratas control. Además las hembras estresadas prenatalmente secretan más CORT durante todo el ciclo diurno (Koehl et al., 1999) Estos efectos son ocasionados en parte, por una reducción de los receptores de GC tipo I y II en el hipocampo (Koehl et al., 1997, 1999).

En los animales estresados prenatalmente, se presentan de forma prematura cambios en el eje HHA que están relacionados con la edad. En las ratas recién nacidas, el periodo hiporresponsivo, en el cual los niveles de esteroides adrenales se mantienen bajos durante las dos primeras semanas de vida posnatal, se encuentra abolido en la descendencia (Henry et al., 1994). Las ratas estresadas prenatalmente de mediana edad presentan aumento en los niveles de GC circulantes en comparación a los animales control (Vallée et al., 1999). La hiperactividad del eje HHA observada tanto en machos como en hembras, es acompañada por incremento en la conducta ansiosa en machos frente a situaciones novedosas (Poltyrev et al., 1996; Vallée et al., 1997; Viltart et al., 2006). Más aún la respuesta conductual de ansiedad frente a situaciones 
novedosas aumenta en machos y hembras (Thompson, 1957; Fride et al., 1986; Wakshlak and Weinstock, 1990; Vallée et al., 1997; Louvart et al., 2005).

Por otro lado, los estresores prenatales de mediana a mayor intensidad han mostrado afectar la neurotransmisión noradrenérgica y dopaminérgica. Se han observado bajos niveles de norepinefrina en la corteza cerebral y en el locus coeruleus junto con la dopamina (Takahashi et al., 1992). También, el estrés prenatal afecta la neurotransmisión glutamatérgica en la corteza prefrontal de la rata macho, por lo que la neurotransmisión se termina debido a la hiperactivación ocasionada por la excesiva presencia de GC (Fumagalli et al., 2009). De esta misma manera, investigaciones han revelado disminución de glutamato y cambios en la expresión del receptor NMDA (reducción en la expresión de la subunidad NR2B) en el hipocampo durante situaciones estresantes en la etapa adulta (Nakamura et al., 2005; Gilbert y Lasley, 2007; Yaka et al., 2007).

\subsubsection{Efectos del estrés prenatal sobre el aprendizaje y la memoria espacial}

El estrés materno por inmovilización aplicado tres veces al día por un periodo de 20-30 minutos, o bien la aplicación de choques eléctricos en las patas, afecta la adquisición de la información espacial en la descendencia cuando realizan la prueba del laberinto acuático de Morris (Weinstock 2007). Estas deficiencias están asociadas entre otras a la reducción de la neurogénesis en el hipocampo, la supresión de la LTP y el aumento de la depresión a largo plazo 
(LTD por sus siglas en inglés) (Ishiwata et al., 2005; Lemaire et al., 2000; Son et al., 2006; Yang et al., 2006).

Por otro lado, deficiencias en el aprendizaje de ratones y ratas estresados prenatalmente, están asociadas con la reducción en la densidad sináptica de las dendritas de las neuronas piramidales en la región CA3 (Ishiwata et al., 2005; Hosseini-sharifabad y Hadinedoushan, 2007). Se ha reportado que el estrés prenatal por inmovilización aplicado desde el día 14 hasta el 20 de gestación disminuye el aprendizaje espacial en los machos de la descendencia pero no en las hembras (Zagron y Weinstock, 2006), lo que sugiere que el desarrollo cerebral en los machos es más sensible a los efectos de las hormonas de estrés de la madre.

En contraste con lo anterior, existen reportes donde las hembras estresadas prenatalmente por inmovilización presentan deterioro en el aprendizaje espacial durante la etapa juvenil (Gue et al., 2004; Wu et al., 2007). Las hembras pero no los machos estresados prenatalmente por inmovilización muestran deterioro en el aprendizaje espacial (Li et al., 2008). En conjunto, los estudios anteriores sugieren que las diferencias entre los machos y las hembras a los efectos del estrés prenatal y sus repercusiones en el aprendizaje espacial, pueden deberse a las diferencias estructurales del hipocampo y en la inducción de LTP (McEwen et al., 1977; Andrade et al., 2000) 


\subsection{Manipulación y estrés}

La manipulación neonatal en ratas ha sido usada para investigar el impacto de condiciones de vida que se presentan en etapas muy tempranas sobre el desarrollo cerebral en especial de la plasticidad neuroconductual (Beane et al., 2002). Existen evidencias que demuestran que en las ratas que experimentan diferentes tipos de estímulos (manipulación o ambientes enriquecidos) durante etapas las tempranas de la vida, ello les permite enfrentar de manera exitosa situaciones estresantes en la vida adulta (Champagne et al., 2009; DeNelsky y Denenberg, 1967; Levine, 1957; Meaney et al., 1985; Plotsky et al., 2005). Estos animales muestran reducción en la conducta ansiosa. Asimismo, en respuesta a un estresor leve, la secreción de corticosterona, prolactina y adrenalina es menor comparada con los animales que no fueron manipulados (Levine et al., 1967; Meaney et al., 1985; Meerlo et al., 1999; Nunez et al., 1996). Por otro lado, los animales manipulados tienen un incremento en los receptores de GC en el hipocampo y la corteza prefrontal (Meaney y Aitken, 1985; Meaney et al., 1994; Viau et al., 1993), así como en la sensibilidad a los CORT en el del eje límbicohipotalámico-hipófisis-adrenal, lo que permite la finalización de la respuesta de estrés de manera rápida.

La manipulación neonatal consiste al menos de tres tipos de manipulación:

1) breve separación maternal (hasta de 15 minutos); 2) estimulación táctil por parte del experimentador y 3) exposición a ambientes novedosos. La separación de la madre elimina el olor y la estimulación táctil y al ser reunidos con la 
progenitora, los recompensa con un mayor contacto físico (Pryce et al., 2001; Villescas et al., 1977). La estimulación táctil por parte del experimentador podría estar simulando la estimulación táctil por parte de la madre. Finalmente, los ambientes enriquecidos ofrecen novedosas estimulaciones tanto olfativas como visuales. En un modelo mixto de manipulación posnatal, que incluye una breve separación de la madre con estimulación táctil por parte del experimentador y exposición a un ambiente novedoso, mostró que, ratas macho en la etapa adulta incrementaran la capacidad de aprender información espacial y no-espacial (Tang, 2001; Tang et al., 2006), también presentan incremento en la LTP hipocampal (Tang y Zou, 2002). Por otro lado, la estimulación táctil puede incrementar la maduración de neuronas corticales (Schapiro y Vukovich, 1970).

\subsubsection{Efectos de la manipulación en animales estresados prenatalmente}

Lee y Rabe (1999) demostraron que las deficiencias en el aprendizaje y las alteraciones en la respuesta de estrés durante la vida posnatal en ratas expuestas a alcohol durante la etapa prenatal, pudieron ser revertidas con la estimulación posnatal diaria que consistió en separación materna y estimulación táctil por un periodo de 3 semanas. En otro estudio donde los animales fueron estresados prenatalmente por inmovilización y acompañados de luz brillante durante la última semana de gestación; ninguno de los grupos experimentales (estresados prenatalmente, estresados prenatalmente con manipulación y control) mostraron alteraciones en la ejecución del laberinto acuático de Morris; sólo se observó que los animales estresados prenatalmente y manipulados con el método de separación breve maternal (desde el día 1 del nacimiento hasta el destete día 21), 
se recuperaban de una experiencia estresante igual que los animales control a diferencia de los animales estresados prenatalmente y que no fueron manipulados (Vallée et al., 1999). Por otro lado, la manipulación posnatal puede revertir completamente las deficiencias en la neurogénesis ocasionadas por el estrés prenatal (Lemaire et al., 2006). Lo anterior podría contribuir a una mejor ejecución en las pruebas cognitivas.

\section{Justificación}

A pesar de que existen investigaciones que evalúan el aprendizaje y la formación de la memoria en animales estresados prenatalmente, los resultados obtenidos son poco claros, inconsistentes y contradictorios, debido en parte a los diferentes esquemas de aplicación del estrés, así como a las distintas intensidades de los estresores utilizados.Asimismo, en los estudios publicados hasta la fecha no se ha evaluado la memoria a largo plazo en los animales estresados prenatalmente. Por lo tanto, en este trabajo se evaluó el efecto de un estresor de alta intensidad (capaz de activar fuertemente al eje HHA) sobre el aprendizaje y la memoria de tipo espacial, a diferentes edades de la vida posnatal. De la misma forma, se evaluó si estos daños pueden ser revertidos mediante la manipulación posnatal. 


\section{Objetivos}

\section{Objetivo general}

Determinar el efecto del estrés prenatal en el aprendizaje y la memoria de tipo espacial en diferentes edades de la vida posnatal de la rata, así como el efecto de la manipulación posnatal en esos parámetros.

\section{Objetivos particulares}

Evaluar el desempeño de las ratas hembras y macho estresadas prenatalmente por inmersión en agua fría en laberinto acuático de Morris a las edades de 1, 2 y 3 meses de vida.

Determinar el efecto de la manipulación posnatal sobre el aprendizaje y la memoria de tipo espacial en ratas hembras y machos de 3 meses estresadas prenatalmente por inmersión en agua fría.

Evaluar el efecto del estrés prenatal por inmersión en agua fría sobre el peso corporal de las ratas hembras y machos en las edades de 1, 2 y 3 meses.

\section{Hipótesis}

La exposición a un estresor de alta intensidad durante la etapa prenatal ocasionará deficiencias en la capacidad de aprender y memorizar información de tipo espacial en ratas hembras y machos en diferentes etapas de la vida posnatal, mismas que serán revertidas por la manipulación posnatal. 


\section{Metodología}

\subsection{Animales}

En la figura 4 se muestran los procedimientos para este estudio. Se utilizaron ratas hembras de la cepa Wistar (Ratus novergicus albinus) en estro de 250 gramos de peso y machos sexualmente expertos de aproximadamente $300 \mathrm{~g}$, adquiridas del bioterio de la Universidad Autónoma Metropolitana unidad Iztapalapa y que permanecieron dentro del mismo durante todos los procedimientos experimentales. Los animales se mantuvieron separados por sexo en grupos de 10 por caja jumbo de plexiglás transparente antes del inicio del apareamiento, a temperatura constante $\left(22 \pm 2^{\circ} \mathrm{C}\right)$, en ciclos de 12 horas de luz y 12 horas de oscuridad (con el comienzo de la fase de luz a las 9 pm (ciclo de luz/oscuridad invertido), con agua y alimento ad libitum. El manejo de los animales y los experimentos se sujetaron a las normas oficiales mexicanas (NOM-062-ZOO1999), así como a la reglamentación de animales domésticos y de laboratorio, publicado en los "Lineamientos para la conducción ética de la investigación, la docencia y la difusión en la División de Ciencias Biológicas y de la Salud" (Mayo 2010). 


\section{Diseño Experimental}

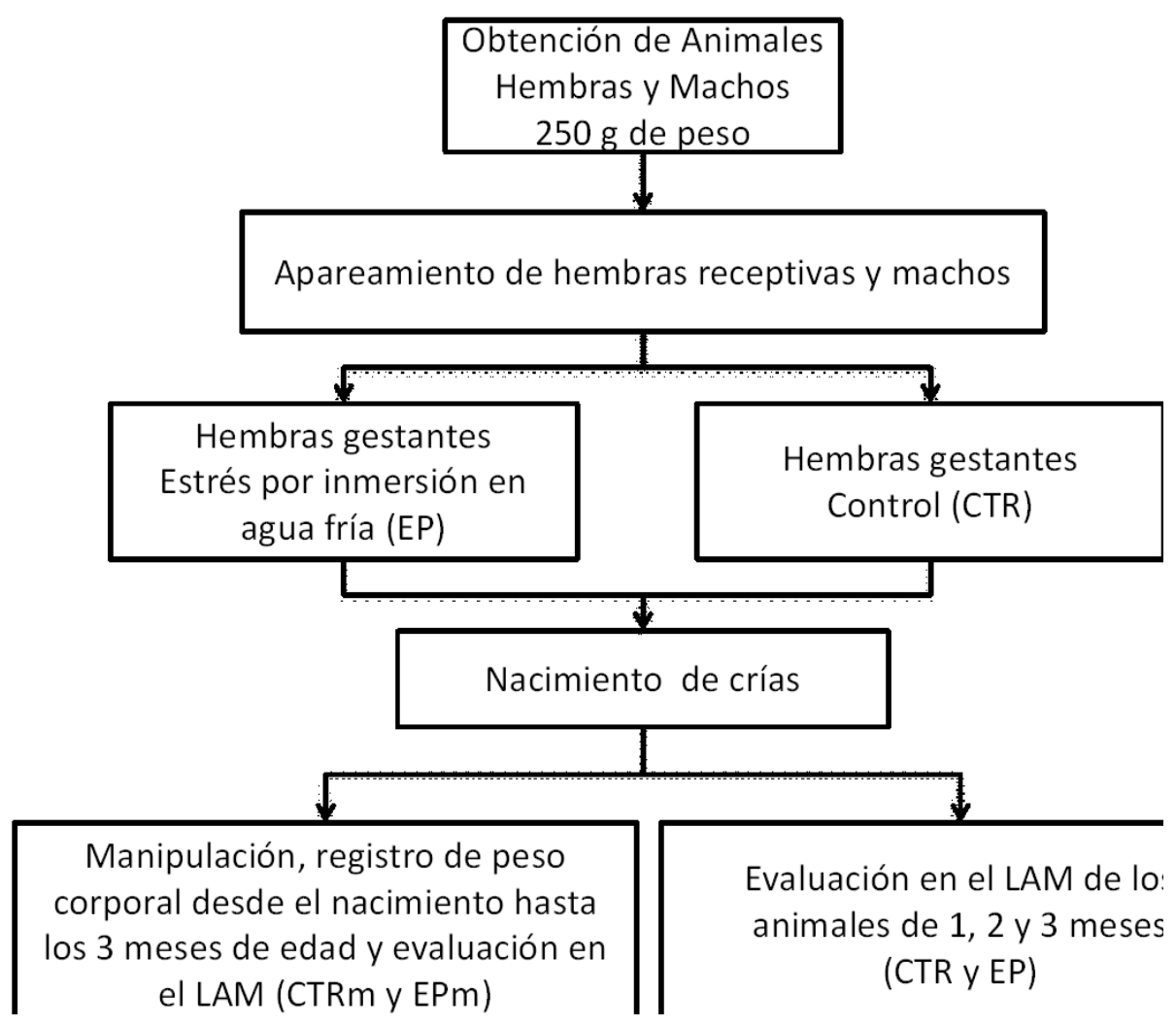

Figura 4. Diseño experimental

Se permitió la libre cópula a parejas conformadas por una hembra en estro y un macho. Los machos eyacularon de 2 a 3 veces. Ese día fue tomado como el día uno de gestación; las hembras fueron asignadas al azar a los grupos control (CTR), estrés prenatal (EP) y se colocaron individualmente en cajas de plexiglás transparente, en las que transcurrió todo el proceso de gestación, nacimiento y crecimiento de las crías hasta el momento en que éstas fueron destetadas (día 21 de vida posnatal) y separadas por sexo. Los grupos experimentales se formaron de acuerdo a la edad y al sexo como se indica en la tabla 1: 
Tabla 1. Grupos experimentales y número de sujetos en cada uno.

\begin{tabular}{|c|c|c|c|c|}
\hline & \multicolumn{2}{|c|}{ HEMBRAS } & \multicolumn{2}{c|}{ MACHOS } \\
\hline & CTR & EP & CTR & EP \\
\hline 1 mes & $\mathrm{n}=8$ & $\mathrm{n}=7$ & $\mathrm{n}=8$ & $\mathrm{n}=7$ \\
\hline 2 meses & $\mathrm{n}=7$ & $\mathrm{n}=10$ & $\mathrm{n}=8$ & $\mathrm{n}=7$ \\
\hline 3 meses & $\mathrm{n}=10$ & $\mathrm{n}=10$ & $\mathrm{n}=12$ & $\mathrm{n}=9$ \\
\hline $\begin{array}{c}3 \text { meses con } \\
\text { Manipulación }\end{array}$ & $\mathrm{n}=8$ & $\mathrm{n}=8$ & $\mathrm{n}=5$ & $\mathrm{n}=5$ \\
\hline
\end{tabular}

Todos los animales fueron colocados en cajas de plexiglás apropiadas al número de individuos y con alimento y agua ad libitum.

\subsection{Estrés Prenatal}

Durante la última semana de gestación (día 15 al 21), las hembras gestantes asignadas al grupo de EP, fueron sometidas a una sola sesión de estrés por inmersión en agua fría, La que consistió en colocar a las ratas de forma individual en una caja de plexiglás con agua a $15^{\circ} \mathrm{C}$ y una profundidad de $15 \mathrm{~cm}$ la misma, durante 15 minutos. La caja fue cubierta con una reja para evitar el escape de las ratas. Procedimiento que se realizó en la última hora de la fase luz (RetanaMárquez et al., 2003). Las hembras asignadas al grupo CTR se mantuvieron en sus cajas y solamente recibieron la limpieza de rutina. 


\subsection{Manipulación y registro de peso corporal}

La manipulación consistió en tomar a las ratas del tronco y colocarlas en una balanza para registrar su peso corporal. La manipulación consistió en tocar a las ratas durante $15 \mathrm{~s}$ continuos; posteriormente se depositaron en una caja diferente a la de procedencia para evitar confusión y que fueran pesadas más de una vez. Al finalizar todas las crías regresaron a la caja con sus madres. El procedimiento se realizó desde el momento del nacimiento hasta la edad de tres meses. El tiempo total del procedimiento para cada animal fue de $30 \mathrm{~s}$. La obtención del peso corporal de las ratas que no fueron manipuladas diariamente se realizó el día en que iniciaron las pruebas conductuales del laberinto acuático de Morris a la edad correspondiente.

\subsection{Paradigma conductual del laberinto acuático de Morris}

\section{(LAM)}

\subsubsection{Instrumentación}

Las pruebas se realizaron en una piscina circular de color verde oscuro, cuyas dimensiones: $170 \mathrm{~cm}$ de diámetro y $50 \mathrm{~cm}$ de altura. Se llenó parcialmente de agua a una altura de $30 \mathrm{~cm}$ y se mantuvo a una temperatura de $21 \pm 2^{\circ} \mathrm{C}$. La piscina se dividió en cuatro cuadrantes imaginarios iguales a los que se les asigno nombre de puntos cardinales (noreste NE, noroeste NO, sureste SE y suroeste SO) tomando como referencia la zona de acceso al laberinto (unicel) y en tres imágenes de colores llamativos que se colocaron en las paredes que también 
cumplieron la función de pistas espaciales durante todas las pruebas. Una plataforma de acrílico transparente $(19 \mathrm{~cm} \times 22 \mathrm{~cm})$ permaneció sumergida por debajo de la superficie del agua $(2 \mathrm{~cm})$ en el cuadrante NE y equidistante de la pared y del centro de la piscina (Figura 5). Los parámetros conductuales que se analizaron fueron: Latencia de escape, que hace referencia al tiempo que tardan las ratas en encontrar la plataforma sumergida durante la fase de aprendizaje y en las memorias de corto y largo plazo.

En las sesiones en las que se retiró la plataforma de la piscina se evaluó: el tiempo de permanencia en el cuadrante que es el tiempo que la rata se encontró dentro del cuadrante NE y el número de cruces del animal sobre la zona donde anteriormente se encontró la plataforma durante la fase de aprendizaje.

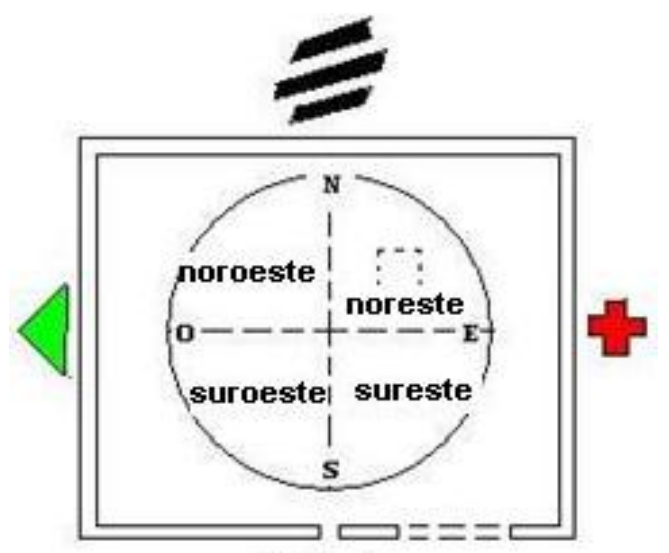

Entrada

Figura 5.- Esquema de los componentes del laberinto acuático de Morris, la ubicación de la plataforma y de las pistas espaciales, así como la división imaginaria de la piscina. 


\subsubsection{Fase de aprendizaje}

Todas las ratas iniciaron las pruebas en el LAM en el cuadrante asignado como SE, cambiando de cuadrante en cada una de las pruebas. Se comenzó situando a la rata dentro del agua con la cabeza apuntando hacia la pared de la piscina. Las ratas que no encontraron la plataforma sumergida después de 60 segundos, fueron dirigidas por el experimentador hacia la misma sobre la superficie del agua, dejándolos por un periodo de 30 segundos sobre la plataforma (Kapoor et al., 2009), este procedimiento sólo se realizó en la primera sesión. La fase de aprendizaje consistió de cuatro sesiones para cada uno de los animales por día, durante cuatro días consecutivos.

\subsubsection{Fase de memoria corto y largo plazo}

La memoria de corto plazo se evaluó 48 horas después del último día de la fase de aprendizaje, las ratas efectuaron un solo ensayo en el LAM, en cual se registró la latencia de escape. Para analizar la capacidad de los animales de recordar la prueba en un mayor periodo de tiempo (memoria de largo pazo), una semana después se realizó un último ensayo; se evaluó la latencia de escape, así como el número de individuos que olvidaron la prueba.

Tres días y ocho días después de la evaluación de se realizaron sesiones sin la plataforma; se evaluó el tiempo de permanencia en el cuadrante donde estuvo la plataforma (NE), así como el número de cruces en ese cuadrante. Los animales permanecieron en la piscina el tiempo máximo asignado (60 s) y fueron videograbados; este procedimiento sólo se realizó una vez para cada animal. 


\section{Análisis estadístico}

Los datos experimentales obtenidos se expresaron como la media \pm error estándar de la media (M.E.E.). El registro de peso corporal, la permanencia en el cuadrante y el número de cruces fueron analizados con ANOVA de una vía. Las pruebas en el LAM se analizaron con ANOVA de medidas repetidas, seguidas por el método de Newman-Keuls de comparaciones post hoc. Las latencias promedio obtenidas en las pruebas de LAM se analizaron con $t$ - student y con ANOVA de una vía. El análisis del porcentaje de los animales que olvidaron la prueba en el día 13 se realizó con la prueba de Chi-Cuadrada. Se consideró diferencia estadística significativa cuando $\mathrm{p}<0.05$.

\section{Resultados}

\subsection{Peso corporal}

Los machos EP de un mes de edad tuvieron pesos corporales significativamente menores que los machos CTR, CTR manipulado y EP manipulado $\left(F_{(3)}=4.80, p<0.01434\right.$, ANOVA de una vía, Newman-Keuls post-hoc, $p$ $<0.05)$. A los 2 y 3 meses de edad no se encontraron diferencias estadísticas en las hembras como en los machos (Figura 6). 

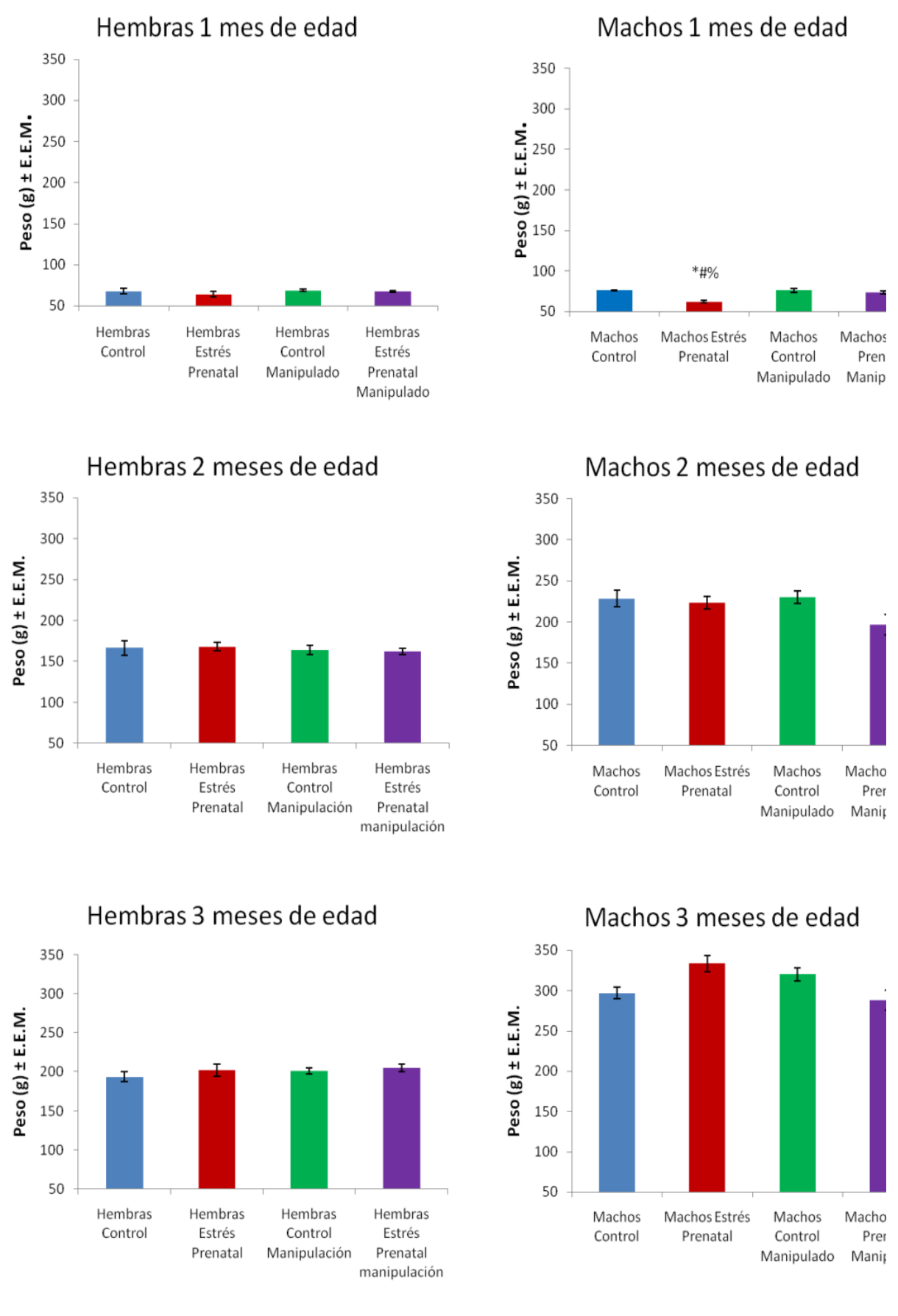

Figura 6.- En las gráficas se muestran los datos correspondientes a los registros del peso corporales en los diferentes sexos y edades de 1, 2 Y 3 meses. Sólo los machos estresados prenatalmente de un mes de edad mostraron menor peso corporal estadísticamente significativo en comparación a los grupos control $\left(^{*}\right)$, control manipulado $(\#)$ y estrés prenatal manipulados $(\%)(F=4.32, p<0.09522)$. 


\subsection{Efectos del estrés prenatal por inmersión en agua fría sobre el aprendizaje y la memoria espacial}

En estos experimentos, los grupos de las diferentes edades y de ambos sexos fueron entrenados para encontrar la plataforma escondida dentro del LAM.

Las latencias de escape de las hembras EP de un mes de edad fueron significativamente mayores que las de las hembras CTR en el día 4 de aprendizaje y en el día $6(A)\left(48\right.$ horas después de la última sesión de aprendizaje $\left(F_{(60)}=4.82\right.$, $p<0.048622$, ANOVA de medidas repetidas, Newman-Keuls post hoc, $p<0.05)$. E tiempo promedio invertido en las pruebas fue estadísticamente mayor en las hembras EP ( $\mathrm{t}=-3.8703, \mathrm{p}<0.000217$, $\mathrm{t}$-student)(Figura 7$)$.

En lo que respecta a la evaluación de la memoria de largo plazo, aunque no se observaron diferencias estadísticas en la latencia de llegada en el día 13, el porcentaje de hembras EP que olvidó la prueba, fue significativamente mayor que el porcentaje de hembras CTR $\left(\mathrm{X}^{2}{ }_{0.05,1}=0.6025\right)$ (tabla 2$)$.

Las latencias de llegada en los machos EP de un mes de edad (B) fue estadísticamente mayor en los días 1, 3, 4 y $13\left(F_{(5-65)}=6.89, p<0.021003\right.$, ANOVA de medidas repetidas, Newman-Keuls post hoc, $\mathrm{p}<0.05$ ), el tiempo promedio de los EP fue estadísticamente mayor a los CTR ( $\mathrm{t}=-3.9713, \mathrm{p}<0.000146$, $\mathrm{t}$-student). (Figura 7). 

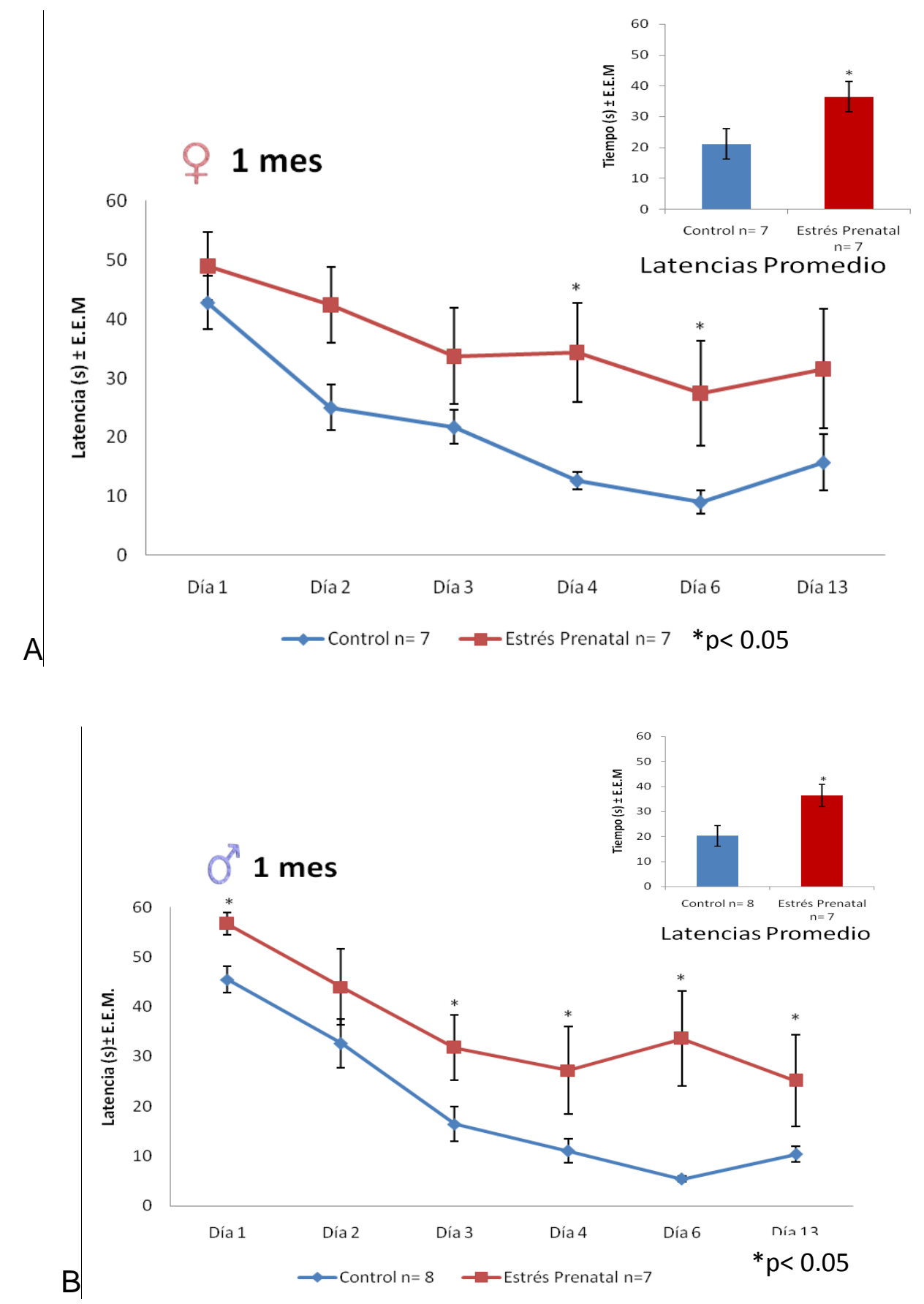

Figura 7.- Las hembras EP de un mes de edad (A) mostraron incrementos significativos en sus latencias de llegada en los días 4 de la fase de aprendizaje y de evaluación de memoria a las 48 horas (día 6) $\left(F_{(5-60)}=4.82, p<0.048622\right.$, ANOVA de medidas repetidas, Newman-Keuls post hoc, $\mathrm{p}<0.05)$ y en las latencias promedio $(\mathrm{t}=-3.8703, \mathrm{p}<0.000217$, $\mathrm{t}$-student). Los machos EP de esta misma edad (B) obtuvieron latencias de llegada significativamente mayores en comparación a los CTR en los días 1, 3, y 4 de aprendizaje, y después de 8 días (Día 13) $\left(F_{(5-65)}=6.89\right.$, p $<0.021003$, ANOVA de medidas repetidas, Newman-Keuls post hoc, $\mathrm{p}<0.05)$. Las latencias promedio de los machos EP es estadísticamente mayor a los CTR ( $\mathrm{t}=-3.9713, \mathrm{p}<0.000146$, $\mathrm{t}$-student). 
Sin embargo, el porcentaje de machos EP de un mes que olvidaron la prueba después de 8 días (día 13) no fue diferente significativamente del grupo CTR (tabla 2).

Tabla 2. Porcentajes de animales que olvidaron la prueba

\begin{tabular}{|c|c|c|c|c|}
\hline & \multicolumn{2}{|c|}{ HEMBRAS } & \multicolumn{2}{c|}{ MACHOS } \\
\hline & CTR & EP & CTR & EP \\
\hline 1 mes & $0 \%$ & $42.8 \%^{*}$ & $0 \%$ & $28.5 \%$ \\
\hline 2 meses & $0 \%$ & $20 \%$ & $0 \%$ & $0 \%$ \\
\hline 3 meses & $0 \%$ & $60 \%{ }^{*}$ & $0 \%$ & $0 \%$ \\
\hline
\end{tabular}

${ }^{*} p<0.05$

Las latencias de escape en las hembras EP de dos meses de edad (A) fueron significativamente mayores en los días 3 y 4 de la fase de aprendizaje, así como en los días 6 y 13 de la fase de memoria $\left(\mathrm{F}_{(5-80)}=5.55, \mathrm{p}<0.03152\right.$, ANOVA de medidas repetidas, Newman-Keuls post hoc, $p<0.05)$. El tiempo promedio invertido por las hembras EP fue estadísticamente mayor a las del grupo CTR ( $t=-$ 4.2937, $\mathrm{p}<0.000039$, t-student) (Figura 8).

Por otro lado, los machos EP de dos meses de edad (B) presentaron latencias de escape significativamente mayores que los machos CTR en los primeros tres días de la fase de aprendizaje $\left(F_{(5-80)}=8.49, p<0.010142\right.$, ANOVA de medidas repetidas, Newman-Keuls post hoc, $\mathrm{p}<0.05)$. 


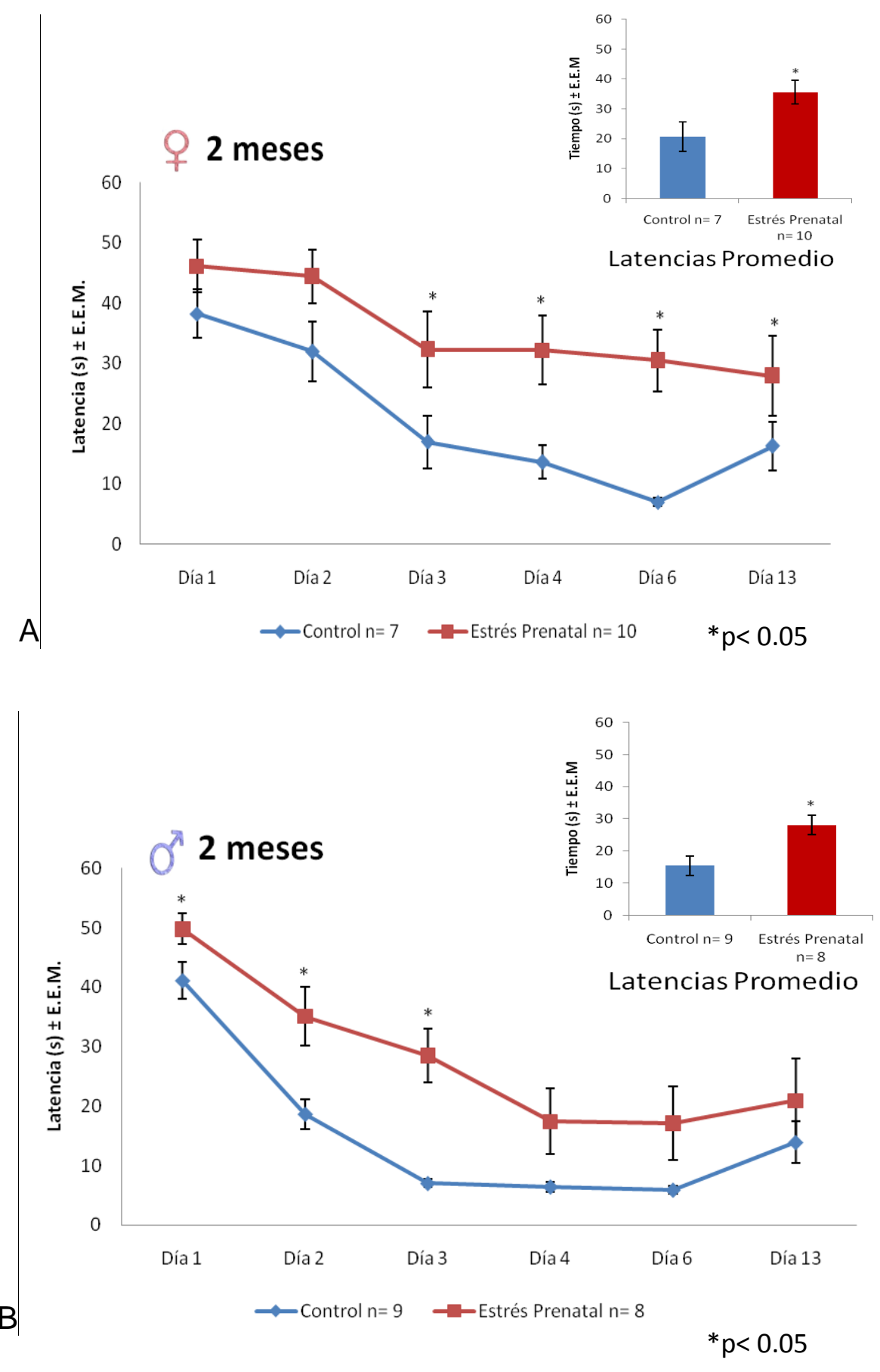

Figura 8.- Las latencias de llegada en los días 3, 4 de aprendizaje, 6 y 13 de evaluación de la memoria del grupo EP fueron significativamente mayores que las CTR $\left(F_{(5-80)}=5.55, p<0.03152\right.$, ANOVA de medidas repetidas, Newman-Keuls post hoc, $\mathrm{p}<0.05$ ). Las latencias promedio de las hembras EP fue significativamente mayor a las de las CTR ( $t=-4.2937, p<0.000039$, $t$-student) (A). Los machos EP (B) mostraron latencias significativamente mayores a los CTR durante los primeros tres días de la fase de aprendizaje $\left(\mathrm{F}_{(5-80)}=8.49, \mathrm{p}<0.010142\right.$, ANOVA de medidas repetidas, Newman-Keuls post hoc, $\mathrm{p}<0.05)$ y latencias promedio mayores en toda la prueba $(\mathrm{t}=-3.9082$, $\mathrm{p}<0.000164$, t-student). 
El tiempo promedio de llegada a la plataforma fue estadísticamente mayor que el de los CTR ( $t=-3.9082, p<0.000164$, $t$-student) (Figura 8).

No se encontraron diferencias significativas en el porcentaje de animales que olvidaron la prueba de los grupos CTR y EP tanto en hembras como machos (tabla 2).

En la hembras de tres meses de edad $(\mathrm{A})$, las hembras EP mostraron mayores latencias de llegada en los días 2, 3 y 4 de la fase de aprendizaje, así como en la fase de memoria, en los días 6 y 13 en comparación a las hembras CTR $\left(F_{(5-90)}=14.20, p<0.001407\right.$, ANOVA de medidas repetidas, Newman-Keuls post hoc, $\mathrm{p}<0.05)$. El tiempo promedio de llegada de las hembras EP fue mayor que el de las hembras CTR ( $t=-5.7410, p<0.000000$, $t$-student) (Figura 9).

De manera similar, los machos EP mostraron latencias de llegada significativamente mayores a las de los machos CTR desde el día 3 de la fase de aprendizaje hasta el último día de prueba en la fase de memoria en el LAM $\left(\mathrm{F}_{(5-}\right.$ 95) $=5.85, p<0.025740$, ANOVA de medidas repetidas, Newman-Keuls post hoc, p<0.05) (Figura 9). El tiempo promedio de los machos EP fue también estadísticamente mayor que el de los CTR ( $\mathrm{t}=-3.5122, \mathrm{p}<0.000621$, $\mathrm{t}$-student).

El porcentaje de hembras EP de 3 meses de edad que olvidaron la prueba en el día 13 fue estadísticamente mayor que el porcentaje de hembras CTR que olvidaron la prueba en ese día $\left(X^{2}{ }_{0.05,1}=8.5714\right)$. Los machos de ambos grupos no mostraron diferencias en el porcentaje de animales que olvidaron la prueba (tabla 2). 

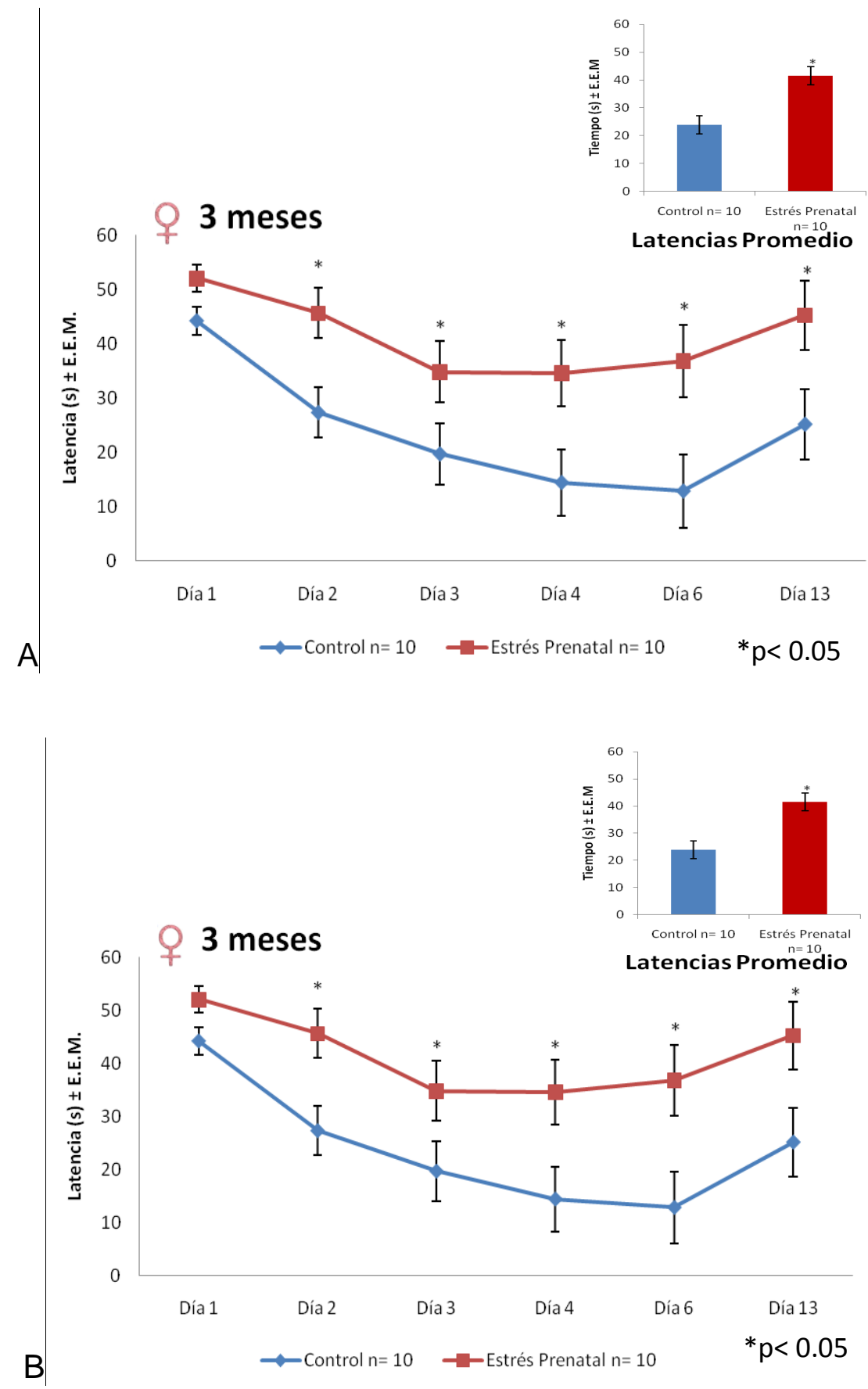

Figura 9.- Las hembras EP de tres meses (A) de edad obtuvieron latencias de llegada significativamente mayores a las CTR desde el día 2 de aprendizaje hasta el final de las pruebas en el LAM $\left(F_{(5-90)}=14.20, p<0.001407\right.$, ANOVA de medidas repetidas, Newman-Keuls post hoc, $\mathrm{p}<0.05)$. El tiempo promedio de llegada de las hembras EP fue mayor que las obtenidas por las CTR ( $t=-5.7410, p<0.000000$, $t$-student). Los machos EP (B) mostraron latencias de llegada significativamente mayores desde el día 3 de aprendizaje hasta el final de las pruebas en el LAM $\left(F_{(5-95)}=5.85, p<0.025740\right.$, ANOVA de medidas repetidas, Newman-Keuls post hoc, $\left.{ }^{*} p<0.05\right)$. El tiempo promedio de llegada de los machos EP fue mayor que el de los CTR ( $\mathrm{t}=-3.5122$, $\mathrm{p}<0.000621$, t-student). 


\subsection{Efectos del estrés prenatal por inmersión en agua fría en el tiempo de permanencia en el cuadrante y número de cruces}

Con el fin de evaluar el grado en que los animales recordaron la ubicación de la plataforma, en la última sesión de la fase de memoria se realizó una prueba en el LAM, pero sin la plataforma en el cuadrante NE. Durante esta sesión, la prueba fue de una duración máxima de $60 \mathrm{~s}$.

Las hembras EP de las tres edades, presentaron menores tiempos de permanencia en el cuadrante NE, donde estuvo la plataforma, en comparación con las hembras CTR. Sin embargo, éstos fueron significativamente menores sólo en las hembras de dos y tres meses de edad $\left(F_{(5)}=4.99, p<0.001204\right.$, ANOVA de una vía, Newman-Keuls post-hoc, $p<0.05$ ) (Figura 11 A). De igual manera, los machos de dos y tres meses permanecieron significativamente menos tiempo dentro del cuadrante NE $\left(F_{(5)}=9.24, p<0.000004\right.$, ANOVA de una vía, NewmanKeuls post-hoc, $p<0.05)$ (Figura $11 \mathrm{~B}$ ).

Por otro lado, las hembras EP de dos y tres meses de edad cruzaron menor número de veces la zona donde se localizó la plataforma en comparación a las CTR $\left(\mathrm{F}_{(5)}=5.28, \mathrm{p}<0.000810\right.$, ANOVA de una vía, Newman-Keuls post-hoc, $\mathrm{p}<$ 0.05) (Figura $12 \mathrm{~A}$ ). Los machos EP de un mes y tres meses de edad cruzaron menor número de veces en comparación a los CTR $\left(F_{(5)}=10.07, p<0.000001\right.$, ANOVA de una vía, Newman-Keuls post-hoc, $\mathrm{p}<0.05$ ) (Figura 12 B). 


\section{A}

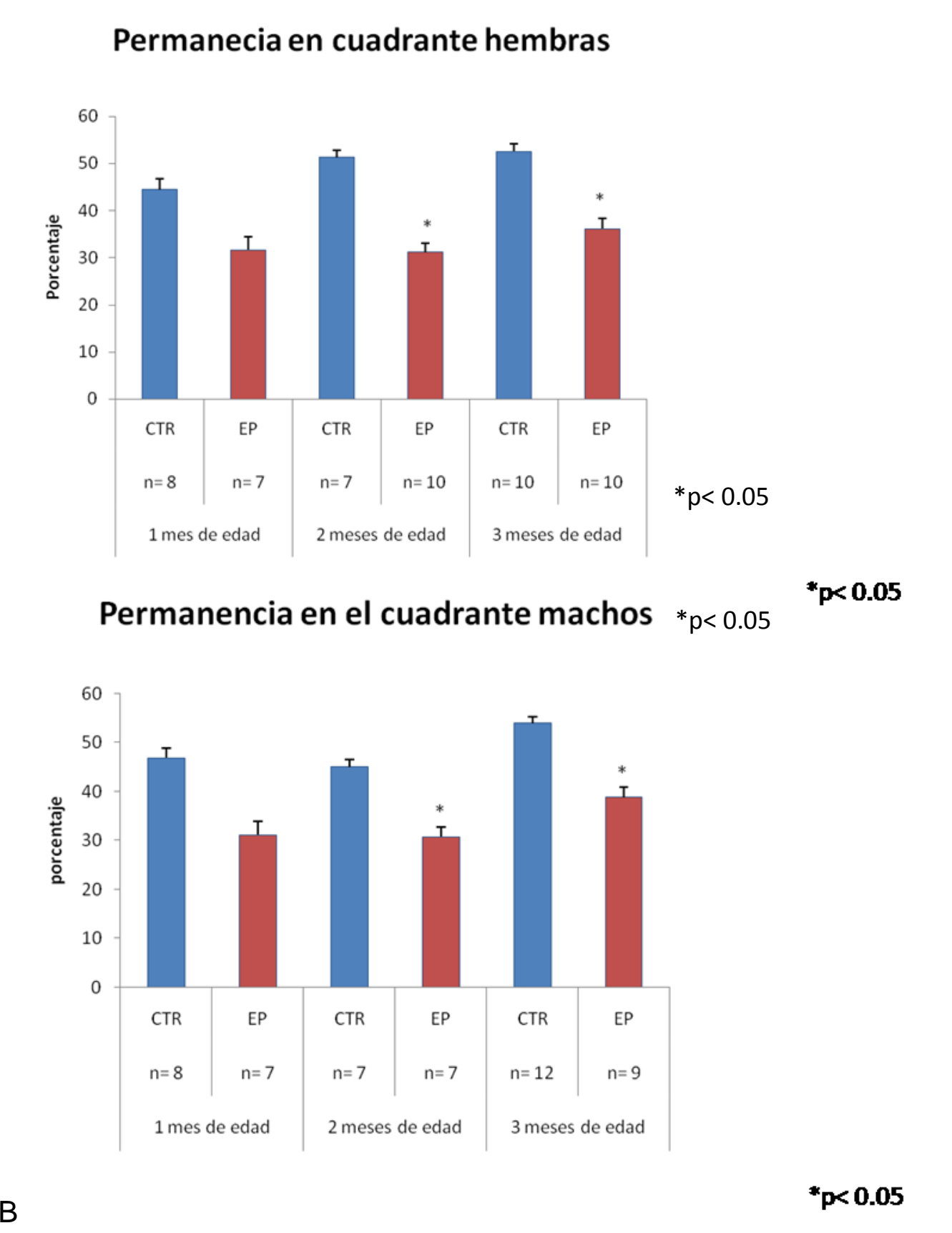

Figura 11.- Hembras EP $(A)\left(F_{(5)}=4.99, p<0.001204\right.$, ANOVA de una vía, Newman-Keuls post-hoc, $p<0.05)$ y machos EP $(B)\left(F_{(5)}=9.24, p<0.000004\right.$, ANOVA de una vía, Newman-Keuls post-hoc, $p$ $<0.05$.) a las edades de 2 y 3 meses permanecieron menos tiempo dentro del cuadrante NE en comparación a los CTR. 


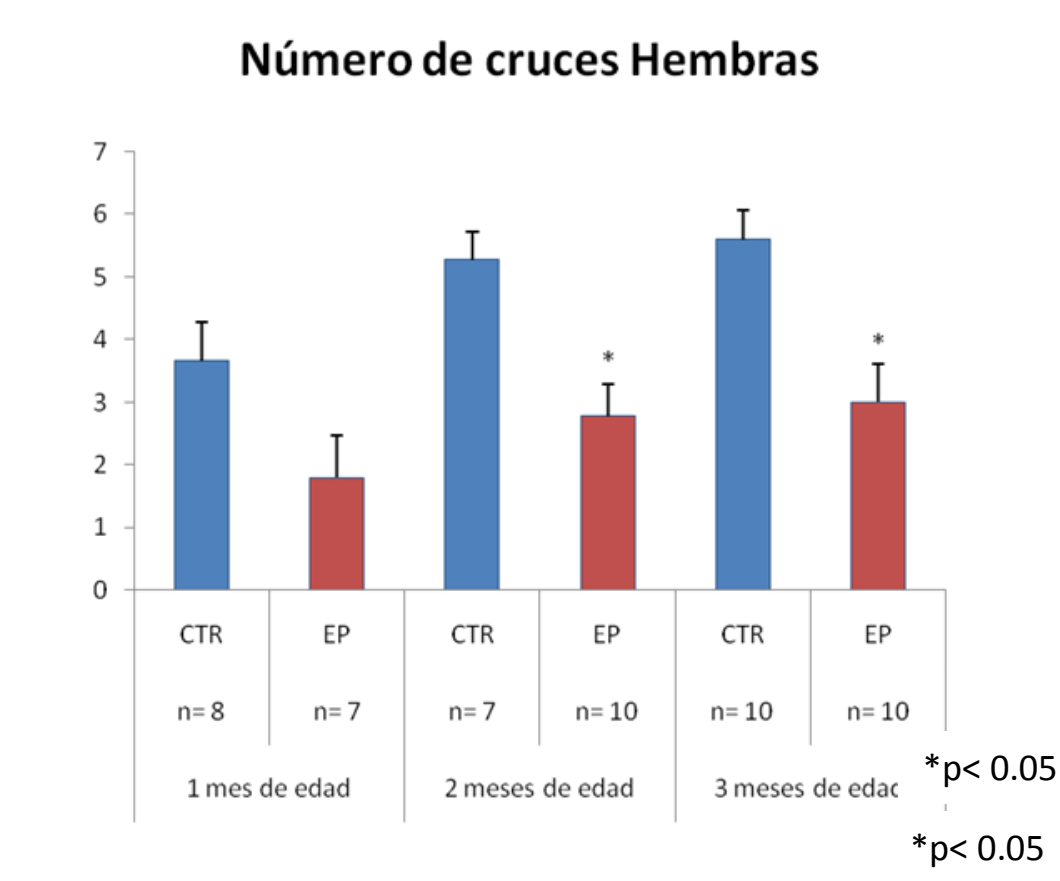

Número de cruces machos

$-p<0.05$

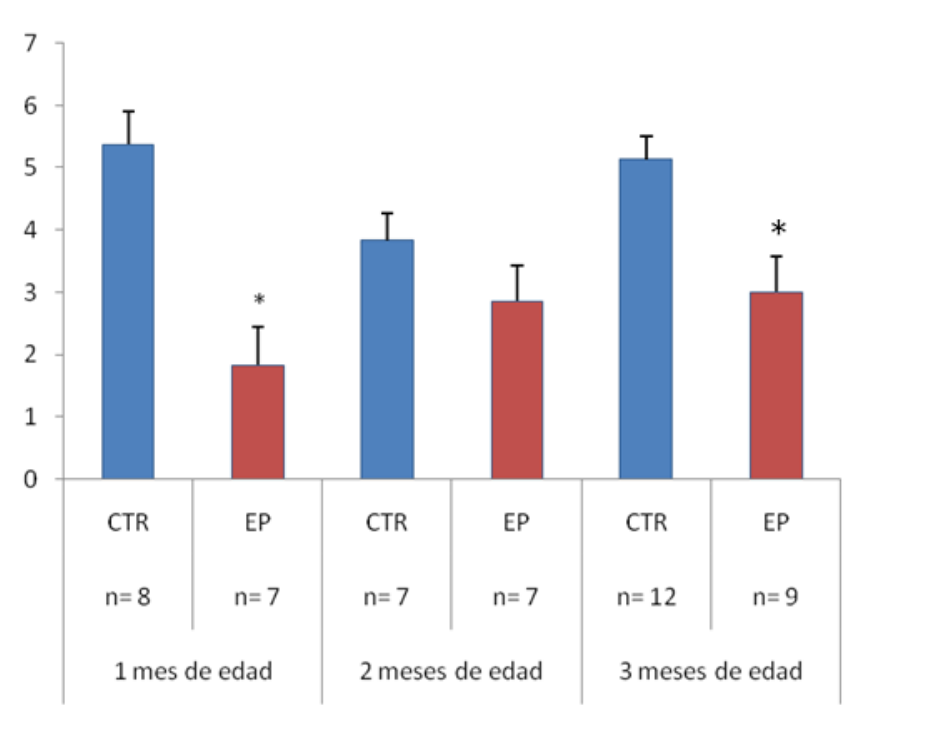

B

${ }^{*} p<0.05$

Figura 12.- Las hembras de dos y tres meses de edad EP cruzaron un menor número de veces sobre la zona de la plataforma $\left(F_{(5)}=5.28, p<0.000810\right.$, ANOVA de una vía, Newman-Keuls posthoc, $p<0.05)$. Los machos EP (B) muestran una disminución en el número de cruces en las edades de uno y tres meses $\left(F_{(5)}=10.07, p<0.000001\right.$, ANOVA de una vía, Newman-Keuls posthoc, $p<0.05$, ANOVA de una vía, Newman-Keuls post-hoc, $p<0.05)$. 


\subsection{Efectos de la manipulación posnatal en animales}

\section{estresados prenatalmente por inmersión en agua fría sobre el}

\section{aprendizaje y la memoria espacial}

Los datos conductuales obtenidos en los animales de tres meses de edad fueron comparados con los animales que fueron manipulados durante registro de su peso corporal.

Las latencias de llegada en el grupo de hembras EP (A) fueron significativamente mayores a partir del día 2 de la fase de aprendizaje, así como en los días 6 y 13 de la fase de memoria $\left(F_{(15-135)}=15.83, p<0.001307\right.$, ANOVA de medidas repetidas, Newman-Keuls post hoc, $p<0.05)$. Por tanto, el tiempo promedio de llegada fue significativamente mayor en comparación con los demás grupos experimentales, EP manipulado, CTR y CTR manipulado $\left(F_{(3)}=15.44\right.$, $p<0.000000$, ANOVA de una vía, Newman-Keuls post-hoc, $p<0.05)$ (Figura 10).

De la misma manera, los machos EP manipulados (B) presentaron latencias de llegada significativamente mayores a las de los otros grupos experimentales (EP, CTR y CTR manipulado) en el día 3 y 4 de la fase de aprendizaje, así como en los días 6 y 13 de la fase de memoria $\left(F_{(15-134)}=55.30\right.$, $p<0.000000$, ANOVA de medidas repetidas, Newman-Keuls post hoc, $p<0.05)$. El tiempo promedio de los machos EP fue estadísticamente mayor sólo con el grupo de machos CTR $\left(F_{(3)}=3.54, p<0.015758\right.$, ANOVA de una vía, Newman-Keuls posthoc, $\left.{ }^{*} p<0.05\right)($ Figura 10). 

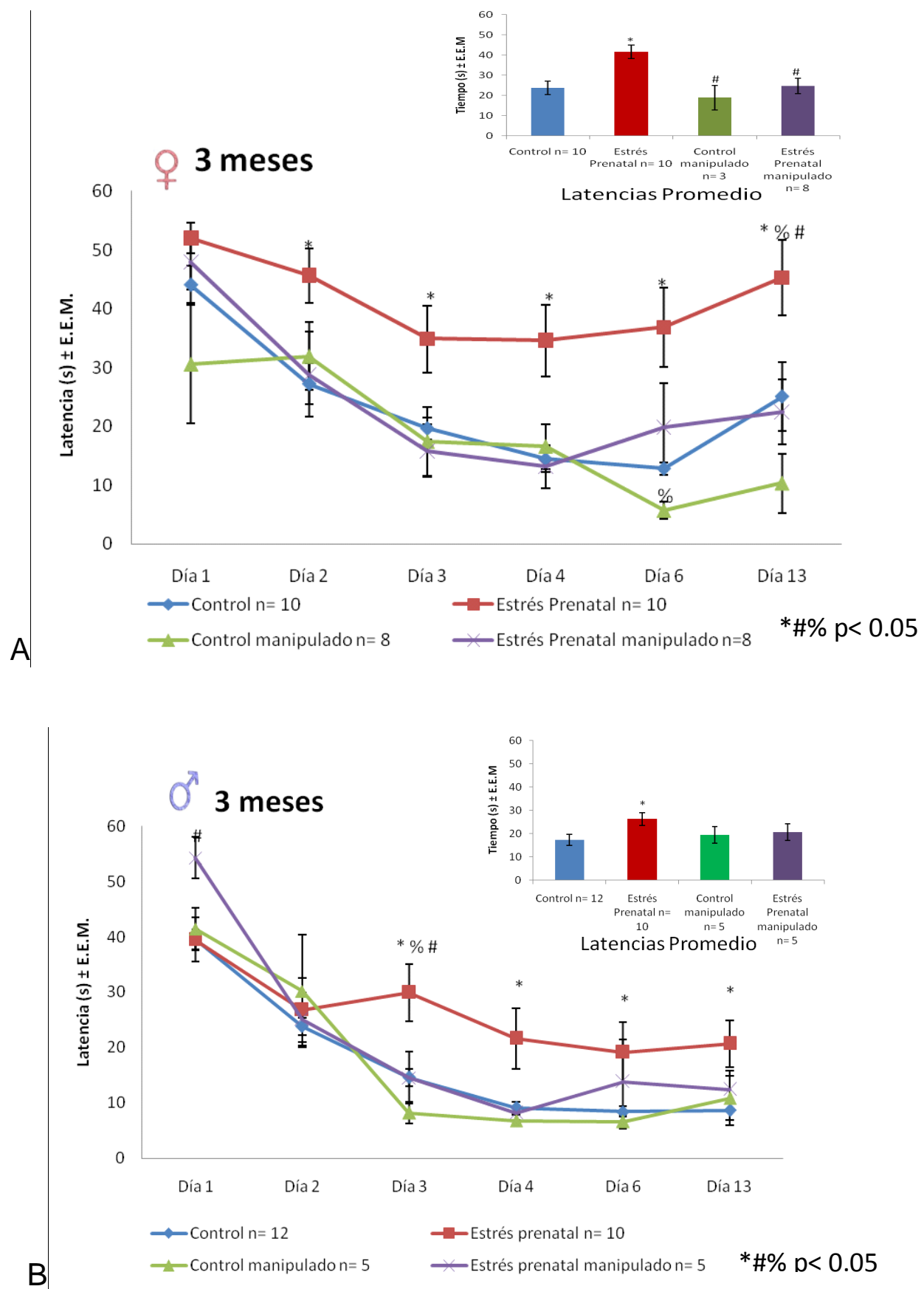

Figura 10.- Las hembras EP (A) obtuvieron latencias de llegada mayores desde el día 2 de aprendizaje y en los días 6 y 13 de memoria en comparación a los otros grupos (*, CTR; \%, CTR manipulado y \#, EP manipulado) $\left(F_{(15-135)}=15.83, p<0.001307\right.$, ANOVA de medidas repetidas, Newman-Keuls post hoc, $p<0.05)$. Las latencias promedio de las hembras EP fue mayor que las de los otros grupos $\left(F_{(3)}=15.44, p<0.000000\right.$, ANOVA de una vía, Newman-Keuls post-hoc, $\left.p<0.05\right)$. Los machos EP (B) mostraron diferencias significativas desde el día 3 y 4 de aprendizaje y los días 6 y 13 de memoria ( ${ }^{*}$, CTR; \%, CTR manipulado y \#, EP manipulado) $\left(F_{(15-134)}=55.30, p<0.000000\right.$, ANOVA de medidas repetidas, Newman-Keuls post hoc, $\mathrm{p}<0.05)$. Las latencias promedio de los machos EP sólo fueron significativamente mayor al grupo de machos CTR $\left(F_{(3)}=3.54, p<0.015758\right.$, ANOVA de una vía, Newman-Keuls post-hoc, $p<0.05$ ). 


\section{Discusión}

De acuerdo con el registro de peso corporal de las ratas utilizadas en este estudio, sólo los machos EP de un mes de edad mostraron disminución en el peso corporal en comparación a los animales de los grupos control del mismo sexo; las hembras no mostraron diferencias en el peso corporal en ninguna de las edades de registro, al igual que los machos de dos y tres meses de edad. Estos resultados concuerdan con lo reportado por Bowman y colaboradores (2004), quienes refieren, con base en el registro de peso corporal realizado diariamente desde el día 20 hasta el 80 de vida posnatal, que el estrés prenatal por inmovilización no modifica el peso de la descendencia de ratas de ambos sexos. Los datos de este trabajo sugieren que el estrés prenatal por inmersión en agua fría y la manipulación no influye en los cuidados maternos y la alimentación que reciben las crías, por lo que su ganancia de peso corporal es similar a las crías control.

Con respecto al proceso de aprendizaje se observó que las latencias llegada, tanto de los animales EP como de los CTR, disminuyeron con las sesiones y las repeticiones. Sin embargo, las latencias de escape fueron estadísticamente diferentes entre los grupos control y experimental, siendo mayores las de los animales EP de todas las edades observadas (uno, dos y tres meses) y en ambos sexos. Estos datos sugieren que las ratas estresadas prenatalmente por inmersión en agua fría tienen deficiencias en el aprendizaje y la memorización de la prueba en el laberinto acuático, independientemente de la edad y del sexo. Estos resultados difieren de lo reportado en otros estudios, en los 
que se observó que sólo las ratas macho estresadas prenatalmente por inmovilización, mostraron deficiencias en el laberinto acuático. En contraste, las hembras no castradas y estresadas prenatalmente mostraron un buen desempeño en la realización de la misma (Nishio et al., 2001; Zagron y Weinstock 2006). Estos autores sugieren que estas diferencias entre sexos podrían atribuirse a un efecto neuroprotector de los estrógenos, los cuales podrían atenuar los efectos del estrés prenatal. Se ha propuesto que las hembras son menos susceptibles a presentar desórdenes cognitivos, gracias a que los estrógenos le ofrecen una acción protectora. Se ha observado que los estrógenos causan incremento en las espinas dendríticas, la LTP y los receptores NMDA en el hipocampo, e influyen en la transmisión colinérgica en el cerebro anterior (Mc Ewen et al., 1997; Tanapat et al., 1999). Sin embargo, otros reportes refieren que las hembras intactas estresadas prenatalmente por inmovilización pero no los machos, muestran deterioro en el aprendizaje espacial (Li et al., 2008). En principio, estos datos contradictorios podrían atribuirse a posibles alteraciones hormonales durante el ciclo estral de las hembras por efecto del estrés prenatal. Sin embargo, se ha corroborado que el estrés prenatal por inmovilización no altera el ciclo estral de las hembras (Beckhardt y Ward, 1983). Además, se ha demostrados que el estrés prenatal por inmovilización no altera los niveles de estrógenos en la etapa adulta (Walf y Frye, 2007). Sin embargo, en este trabajo se utilizó un estresor de alta intensidad, la inmersión en agua fría y es posible que este estresor pudiera haber causado alteraciones en los niveles de estrógenos en la etapa juvenil y adulta, evitándose así sus efectos protectores, favoreciendo las deficiencias observadas 
en el aprendizaje, de manera similar a los machos. Además, la mayor respuesta del eje HHA al estrés en las hembras ocasiona que los niveles elevados de corticosteroides después de una situación estresante no puedan regresar a los niveles basales (Koehl et al., 1999). Esto favorecería aún más los efectos adversos en el aprendizaje y la memoria en las hembras.

Por otra parte, es importante mencionar que el estresor utilizado en este trabajo (inmersión en agua fría) causa una respuesta más intensa, en términos de activación del eje adrenal, que el estrés por inmobilización (Retana-Márquez, et al., 2003). Así, las alteraciones en el desempeño en las pruebas de aprendizaje en las ratas de ambos sexos pueden atribuirse a los efectos de los elevados niveles de corticosterona causados por el estrés durante la gestación. Esto podría explicar por qué se observa deterioro similar en la capacidad de aprendizaje de hembras y machos. La menor capacidad de aprendizaje observada en las ratas estresadas prenatalmente podría explicarse por una menor plasticidad en el hipocampo de estos animales. Se sabe que el área CA1 del hipocampo presenta disminución en la potenciación de largo plazo y que dicho mal funcionamiento se mantiene y se manifiesta hasta la edad adulta (Son et al., 2006).

Estos resultados permiten concluir que el estrés prenatal es capaz de deteriorar la capacidad de aprendizaje en la etapa juvenil y adulta, independiente de la condición sexual y hormonal del individuo.

Un dato importante que aporta este estudio es el relacionado con la memoria de largo plazo. Como muestran los resultados, al poner a prueba a las 
ratas en una situación en la que debieron recordar la prueba 8 días después de la última exposición al paradigma cognitivo, las ratas de ambos sexos, estresadas prenatalmente, presentaron problemas al recordar la posición de la plataforma. Estos resultados indican que las ratas estresadas prenatalmente presentan deficiencias en el almacenamiento de la información y su posterior recuerdo. Esta inhabilidad utilizar las pistas espaciales disponibles para ubicarse de manera exitosa en el laberinto y para poder encontrar la plataforma, concuerda con lo reportados por Yang y colaboradores (2006). Las ratas macho estresadas prenatalmente cruzan menor número de veces sobre la zona donde se encontraba la plataforma escondida durante la fase de aprendizaje. En el caso de las hembras, no se encuentran datos en la literatura acerca de alteraciones en la memoria de largo plazo, por lo que esta es una aportación del presente trabajo. Las ratas hembras también muestran deficiencia en la memoria espacial, ya que el tiempo que permanecieron en el cuadrante donde se encontraba anteriormente la plataforma, así como el número de cruces en ese cuadrante disminuyó significativamente,

Las diferencias en el aprendizaje y la memoria encontradas en este trabajo en comparación con otros estudios, donde utiliza otro tipo de estresor, podrían estar relacionadas con sus intensidades. Se sabe que, la inmovilización es un estresor de mediana intensidad y que al aplicarlo de forma repetida causa habituación. El estresor de mediana intensidad aplicado en ratas, tiene como resultado una robusta secreción inicial de corticosterona, la que disminuye gradualmente en el transcurso de los días de exposición al estresor (Natelson et 
al., 1988; Pitman et al., 1988; Retana-Márquez et al., 2003). La inmersión en agua fría no ocasiona habituación; Retana-Márquez y colaboradores (2003) han demostrado que en las ratas expuestas durante 20 días a este estresor los niveles de corticosterona se incrementaron 3.7 veces por arriba de los niveles normales y permanecen elevados durante todo el tiempo de exposición al estresor. Con lo anterior se puede proponer que, los altos niveles de corticosterona presentes en el plasma de los fetos durante el último periodo de gestación podrían estar afectando su desarrollo cerebral.

De esta manera, los efectos del estrés prenatal sobre el aprendizaje y memoria espacial en los animales de este estudio, puede ser el resultado de la exposición a altos niveles de corticosteroides durante su desarrollo fetal. Considerando que el hipocampo es una estructura cerebral implicada en el procesamiento de la información espacial, ésta es una de las principales estructuras blanco de los corticosteroides durante el desarrollo cerebral. En diferentes estudios se ha observado que los animales estresados prenatalmente presentan disminución en la arborización dendrítica y en la densidad de las espinas dendríticas y sinapsis (Hayashi et al., 1998; Ishiwata et al., 2005; Barros et al., 2006), decremento en los segmentos dendríticos y ramificaciones de las células granulosas y piramidales en CA3 (Hosseini-Shrifabad y Hadinedoushan, 2007), reducción en la proliferación celular, en el contenido del factor neurotrófico derivado del cerebro (BDNF) (Van Den Hove et al., 2006), en la neurogénesis y volumen total del hipocampo (Lemaire et al., 2000; Coe et al., 2003). Por otro lado se sabe que los receptores de corticosteroides disminuyen en la etapa adulta, y 
que esta disminución está implicada en la alteración del mecanismo de regulación del eje HHA (Maccari et al., 1995; de Kloet et al., 1998, Van Waes et al., 2006).

En la construcción del aprendizaje y la memoria, no sólo interviene una sola estructura cerebral, sino, un conjunto estructuras cerebrales y procesos conductuales que trabajan en conjunto durante el aprendizaje. La depresión, la ansiedad, el miedo exacerbado a las situaciones novedosas y las alteraciones en la reactividad del eje adrenal son característicos de los individuos estresados prenatalmente (Henry et al., 1994; Maccari et al., 1995; Vallée et al., 1997; MorleyFletcher et al., 2003a, b) y tienen relación de manera importante con los altos niveles de corticosteroides en plasma.

Como se puede observar en este trabajo, tanto las hembras como los machos se ven afectados por el estrés prenatal y las diferencias entre sexos no se hacen presentes como en estudios anteriores, donde se menciona que los problemas en el aprendizaje espacial en animales estresados prenatalmente están relacionados con las diferencias en la estructura hipocampal y en la inducción de LTP de hembras y machos (Andrade et al., 2000; McEwen et al., 1977). Posiblemente, las ratas estresadas prenatalmente en este trabajo, podrían tener mayores daños en el hipocampo y otras estructuras cerebrales implicadas en el aprendizaje espacial, a diferencia de los animales estresados prenatalmente con un estresor de mediana intensidad.

Se ha observado que la conducta ansiosa es característica de los animales estresados prenatalmente (Meerlo et al., 1999; Nunez et al., 1995; Vallée 
et al., 1997; Steimer et al., 1998) y en situaciones novedosas, como lo es una prueba cognitiva, los animales experimentan estrés y ansiedad. Estas respuestas van disminuyendo con la continua exposición a la prueba. Sin embargo, en los animales estresados prenatalmente esto puede no ocurrir y el estrés ocasionado por la prueba puede ser un continuo obstáculo para que el desempeño mejore paulatinamente. La manipulación postnatal puede revertir la hiperactividad del eje HHA en los animales estresados prenatalmente y cambiar la forma en que responden a los estímulos estresantes (Levine, 1957). Esto se debe al incremento de los receptores a corticosteroides tipo II (GR) en el hipocampo, de esta forma aumenta la sensibilidad del sistema de retroalimentación negativa (Meaney et al., 1989), permitiendo que el estrés de la prueba no interfiera en el desempeño.

En este trabajo se observó que la manipulación mejoró el desempeño en la prueba cognitiva de los animales estresados prenatalmente a la edad de tres meses de edad de ambos sexos. Es probable que dicho desempeño se deba a un regreso más eficiente al estado basal del eje adrenal después de los estímulos estresantes, de esta forma permitiendo que los niveles de corticosteroides permanezcan por debajo del punto de toxicidad y no afecten a las neuronas en el hipocampo y que el periodo hiporesponsivo durante las primeras semanas de vida posnatal se presente de manera normal, lo que permite que la proliferación neuronal en el hipocampo se lleve a cabo de manera normal durante esta etapa de la vida. Estos datos son acordes con lo reportado por otros autores, quienes han demostrado que la manipulación es capaz de mejorar el desempeño de los sujetos en el aprendizaje y la memoria de tipo espacial (Stamatakis et al., 2008). 
En el presente trabajo, además de el desempeño en el aprendizaje y la memoria de corto plazo, se evaluó la memoria de largo plazo en los animales estresados prenatalmente y manipulados postnatalmente. Los datos muestran que la manipulación mejora definitivamente el aprendizaje y la memoria en los animales con estrés prenatal. Estos confirman que la manipulación mejora sensiblemente el aprendizaje y la memoria de corto y largo plazo en los animales estresados prenatalmente. Es probable que la mejora en el aprendizaje y la memoria en los animales manipulados postnatalmente estén relacionadas con la neurogénesis en el hipocampo. Se ha demostrado que el estrés prenatal causa déficit en la neurogénesis del hipocampo y que la estimulación postnatal contrarresta dicho déficit, manteniendo la neurogénesis en el giro del hipocampo al mismo nivel que el control no estresado (Lemaire et al., 2006).

\section{Conclusiones}

El estrés prenatal causa deficiencias en el aprendizaje y memoria espacial de corto y largo plazo en diferentes etapas de la vida posnatal. Los efectos del estrés prenatal son similares en hembras y machos.

La manipulación posnatal revierte los efectos nocivos del estrés prenatal en el aprendizaje y la memoria espacial de corto y largo plazo. 


\section{Bibliografía}

Aguilera, G., Subburaju, S., Young, S., Chen, J. (2008). The parvocellular vasopressinergic system and responsiveness of the hypothalamic pituitary adrenal axis during chronic stress. Progress in Brain Research.170:29-39.

Andrade, J. P., Madeira, M. D., Paula-Barbosa, M. M. (2000). Sexual dimorphism in the subiculum of the rat hippocampal formation. Brain Research. 875(1-2):125-137.

Bailey, C. H., Kandel, E. R. (1993). Structural changes accompanying memory storage. Annual Review of Physiology. (55):397-426.

Baldi, E., Bucherelli, C. (2005). The inverted "U-shaped" doseeffect relationships in learning and memory: modulation of arousal and consolidation, Nonlinearity in Biology. Toxicology, and Medicine. (3):9-21.

Beane, M. L., Cole, M., Spencer, R. L., Rudy, J. W. (2002). Neonatal handling enhances contextual fear conditioning and alters corticosterone stress responses in young rats. Hormones and Behavior. 41(1):33-40.

Barros, V. G., Duhalde-Vega, M., Caltana, L., Brusco, A., Antonelli, M. C. (2006). Astrocyte neuron vulnerability to prenatal stress in the adult rat brain. Journal of Neuroscience Research. 83(5):787-800.

Beckhardt, S., Ward, I. L. (1983). Reproductive functioning in the prenatally stressed female rat. Developmental Psychobiology.16(2):111-118.

Beversdorf, D. Q., Manning, S. E., Hillier, A., Anderson, S. L., Nordgren, R. E., Walters, S. E., Nagaraja, H. N., Cooley, W. C., Gaelic, S. E., Bauman, M. L. (2005). Timing of prenatal stressors and autism. Journal of Autism and Developmental Disorders. (35):471-478.

Bloom, F. E., Battenberg, E. L., Rivier, J., Vale, W. (1982). Corticotropin releasing factor (CRF): immunoreactive neurones and fibers in rat hypothalamus. Regulatory Peptides. 4(1):43-48

Bohus, B., De Kloet, E., Veldhuis, H. (1983). Adrenal steroids and behavioral adaptation: Relationships to brain corticoid receptors. In. Ganten, R.; Pfaff, D., eds. Progress in Neuroendocrinology (2). 1: Berlin: Springer-Verlag .

Bowman, R. E., Beck, K. D., Luine, V. N. (2003). Chronic stress effects on memory: sex differences in performance and monoaminergic activity. Hormones and Behavior 43(1):48-59.

Bowman, R. E., MacLusky, N. J., Sarmiento, Y., Frankfurt, M., Gordon, M., Luine, V. N. (2004). Sexually dimorphic effects of prenatal stress on cognition, 
hormonal responses, and central neurotransmitters. Endocrineology 145(8):37783787.

Brandt, M. D., Maass, A., Kempermann, G., Storch, A. (2010). Physical exercise increases Notch activity, proliferation and cell cycle exit of type-3 progenitor cells in adult hippocampal neurogenesis. European Journal of Neuroscience. 32:1256-1264.

Brown, E. S., Rush, A. J., McEwen, B. S. (1999). Hippocampal remodeling and damage by corticosteroids: implications for mood disorders. Neuropsychopharmacology 21(4):474-484.

Cahill, L., McGaugh, J. L. (1996). Modulation of memory storage. Current Opinion Neurobiology. 6(2):237-242.

Cahill, L., McGaugh, J. L., Weinberger, N. M. (2001). The neurobiology of learning and memory: some reminders to remember. Trends in Neurosciences. 24(10):578-581 .

Casadio, A., Martin, K. C., Giustetto, M., Zhu, H., Chen, M., Bartsch, D. Bailey, C. H., Kandel, E. R. (1999). A transient, neuron-wide form of CREBmediated long-term facilitation can be stabilized at specific synapses by local protein synthesis. Cell. 99(2):221-237.

Castellano, C., Puglisi-Allegra, S. (1983). Strain-dependent modulation of memory by stress in mice. Behavioral and Neural Biology. 38(1):133-138.

Castro, R., Peek-Asa, C., Ruiz, A. (2003). Violence against women in Mexico: a study of abuse before and during pregnancy. American Journal of Public Health 93(7): 1110-1116.

Champagne, F. A., Curley, J. P., Swaney, W. T., Hasen, N. S., Keverne, E. B. (2009). Paternal influence on female behavior: the role of Peg3 in exploration, olfaction, and neuroendocrine regulation of maternal behavior of female mice. Behavioral Neuroscience. 123(3):469-480.

Charil, A., Laplante, D. P., Vaillancourt, C., King, S. (2010). Prenatal stress and brian development. Brain Research Reviews. 65(1):56-79.

Charmandari, E., Tsigos, C., Chrousos, G. (2005). Endocrinology of the stress response. Annual Review of Physiology. 67:259-84.

Chrousos, G. P., Kino, T. (2007). Glucocorticoid action networks and complex psychiatric and/or somatic disorders. Stress.10(2):213-219.

Cliver, S. P., Goldenburg, R. L., Cutter, G. R., Hoffman, H. J., Copper, R. L., Gotlieb, S. J., Davis, R. O. (1992). The relationships among psychosocial profile, maternal size, and smoking predicting fetal growth retardation. Obstetrics and Gynecology. 80(2):262-267. 
Coe, C. L., Kramer, M., Czéh, B., Gould, E., Reeves, A. J., Kirschbaum, C., Fuchs, E. (2003). Prenatal stress diminishes neurogenesis in the dentate gyrus of juvenile rhesus monkeys. Biological Psychiatry 54(10):1025-1034.

Conrad, C. D. (2005). The relationship between acute glucocorticoid levels and hippocampal function depends upon task aversiveness and memory processing stage. Nonlinearity in Biology, Toxicology and Medicine 3(1):57-78.

Cordero, M. I., Merino, J. J., Sandi, C. (1998). Correlational relationship between shock intensity and corticosterone secretion on the establishment and subsequent expression of contextual fear conditioning. Behavioral Neuroscience. 112(4):885-891.

Crabbe, J. C.,.Wahlsten, D., Dudek B. C., (1999). Genetics of mouse behavior: interactions with laboratory environment, Science. 284:1670-1672.

Croiset, G., Nijsen, M. J., Kamphuis, P. J., (2000). Role of corticotropinreleasing factor, vasopressin and the autonomic nervous system in learning and memory. European Journal of Pharmacology. 405(1-3):225-234

De Kloet, E. R., Vreugdenhil, E., Oitz, M: S., Joels, M. (1998). Brain corticosteroid receptor balance in health and disease. Endocrine Reviews. 19(3):269-301.

De Kloet, E. R., Oitzl, M. S., Joels, M. (1999). Stress and cognition: are corticosteroids good or bad guys? Trends Neurosciences. 22(10):422-426.

De Kloet, E. R., Rotteveel, F., Voorhuis, T. A., Terlou, M. (1985). Topography of binding sites for neurohypophyseal hormones in rat brain. European Journal of Pharmacology. 110(1):113-119.

DeNelsky, G. Y., Denenberg, V. H. (1967). Infantile stimulation and adult exploratory behaviour in the rat: effects of handling upon visual variation-seeking. Animal Behaviour. 15(4):568-573.

de Quervain, D. J.-F., Roozendaal, B., McGaugh, J. L. (1998). Stress and glucocorticoids impair retrieval of long-term spatial memory. Nature 394(6695): 787-790.

Diamond, D. M., Bennett, M. C., Stevens, K. E., Wilson, R. L., Rose, G. M. (1990). Exposure to a novel environment interferes with the induction of hippocampal primed burst potentiation in the behaving rat. Psychobiology 18 , 273281.

Diamond, D. M., Fleshner, M., Ingersoll, N., Rose, G. M. (1996). Psychological stress impairs spatial working memory: relevance to electrophysiological studies of hippocampal function. Behavioral Neuroscience. 110(4):661-672. 
Diamond, D. M., Fleshner, M., Rose, G. M. (1994). Psychological stress repeatedly blocks hippocampal primed burst potentiation in behaving rats. Behavioural Brain Research. 62(1):1-9.

Diamond, D. M., Park, C. R. (2000). Predator exposure produces retrograde amnesia and blocks synaptic plasticity. Progress toward understanding how the hippocampus is affected by stress. Annals of New York Academy of Science. 911, 453-455.

Diamond, D. M., Park, C. R., Campbell, A. M., Woodson, J. C. (2005). Competitive interactions between endogenous LTD and LTP in the hippocampus underlie the storage of emotional memories and stress-induced amnesia. Hippocampus 15(8):1006-1025.

Diamond, D. M., Park, C. R., Heman, K. L., Rose, G. M. (1999). Exposing rats to a predator impairs spatial working memory in the radial arm water maze. Hippocampus 9(5):542-552.

Diaz-Olavarrieta, C., Ellertson, C., Paz, F., de Leon S. P., AlarconSegovia, D. (2002). Prevalence of battering among 1780 outpatients at an internal medicine institution in Mexico. Social Science and Medicine. 55(9):1589-602.

Eichenbaum, H. (1997). How does the brain organize memories? Science 277(5324):330-332.

Eichenbaum, H. (2000). A cortical-hippocampal system for declarative memory. Reviews in the Neurosciences. 1(1):41-50.

Eichenbaum, $H$ (1999). The hippocampus and mechanisms of declarative memory. Behavioural Brain Research. 103(2):123-133.

Engert, F., Bonhoeffer, T. (1999). Dendritic spine changes associated with hippocampal long-term synaptic plasticity. Nature 399(6731):66-70.

Fletcher, P.C., Shallice, T., Frith, C. D., Frackowiak, R. S., Dolan, R. J. (1996). Brain activity during memory retrieval. The influence of imagery and semantic cueing. Brain. 119(pt 5):1587-1596.

Fride, E., Dan, Y., Feldon, J., Halevy, G., Weinstock, M., (1986). Effects of prenatal stress on vulnerability to stress in prepubertal and adult rats. Physiology and Behavior. 37(5):681-687.

Fox, S. E., Ranck, J. B., Jr. (1975). Localization and anatomical identification of theta and complex spike cells in dorsal hippocampal, formation of rats. Experimental Neurolgy. 49:299-313

Fujioka, A., Fujioka, T., Ishida, Y., Maekawa, T., Nakamura, S. (2006). Differential effects of prenatal stress on the morphological maturation of hippocampal neurons. Neuroscience. 141:907-915. 
Fujioka, T., Fujioka, A., Tan, N., Chowdhury, G. M. I., Mouri, H., Sakata, Y., Nakamura, S. (2001). Mild prenatall stress enhances learning performance in the non-adopted rat offspring. Neuroscience. 103(2):301-307.

Fumagalli, F., Pasini, M., Frasca, A., Drago, F., Racagni, G., Riva, M. A. (2009). Prenatal stress alters glutamatergic system responsiveness in adult rat prefrontal cortex. Journal of Neurochemistry. 109(6):1733-1744.

Gabrielli, J. D. E. (1998). Cognitive neuroscience of human memory. Annual Review Psychology. 49, 87-115.

Ganong, W. F., Alpert, L. C., Lee, T. C. (1974). ACTH and the regulation of adrenocortical secretion. The New England. Journal of Medicine 290(18):10061011.

Gilbert, M. E., Lasley, S. M. (2007). Developmental lead (Pb) exposure reduces the ability of the NMDA antagonist MK- 801 to suppress long-term potentiation (LTP) in the rat dentate gyrus, in vivo. Neurotoxicology and Teratology. 29(3):385-393.

Gould, E., Beylin, A., Tanapat, P., Reeves, A., Shors, T. J. (1999). Learning enhances adult neurogenesis in the hippocampal formation. Nature Neuroscies. 2(3):260-265.

Gould, E., Gross, C. G. (2002) Neurogenesis in adult mammals: some progress and problems. Journal of Neuroscience. 22(3):619-623.

Gould, E., McEwen, B. S., Tanapat, P., Galea, L. A., Fuchs, E. (1997). Neurogenesis in the dentate gyrus of the adult tree shrew is regulated by psychosocial stress and NMDA receptor activation. Journal of Neuroscience. 17(7):2492-2498.

Grizenko, N., Shayan, Y. R., Polotskaia, A., Ter-Stepanian, M., Joober, R. (2008). Relation of maternal stress during pregnancy to symptom severity and response to treatment in children with ADHD. Journal of Psychiatry and Neuroscience. 33(1):10-16.

Gué, M., Bravard, A., Meunier, J., Veyrier, R., Gaillet, S., Recasens, M., Maurice, T. (2004). Sex differences in learning deficits induced by prenatal stress in juvenile rats. Behavioral and Brain Research. 150(1-2):149-157.

Habib, K. E., Gold, P. W., Chrousos, G. P. (2001). Neuroendocrinology of stress. Endocrinology and Metabolism Clinics of North America. 30(3):695-728.

Hayashi, A., Nagaoka, M., Yamada, K., Ichitani, Y., Miake, Y., Okado, N. (1998). Maternal stress induces synaptic loss and developmental disabilities of offspring. International Journal for Developmental Neurosciences. 16(3-4):209-219. 
Hebb, D. O. (1949) The Organization of Behavior: a Neuropsychological Theory. Wiley and Sons, Inc., New York, 335 p.

Hebb, D. O. (1976). Physiological learning theory. Journal of Abnormal. Child Psychology. 4(4):309-314.

Henry, C., Kabbaj, M., Simon, H., Moal, M., Maccari, S. (1994). Prenatal stress increases the hypothalamo-pituitary-adrenal axis response in young and adult rats. Journal of Neuroendocrinology. 6(3):341-345.

Hosseini-sharifabad, M., Hadinedoushan, H. (2007). Prenatal stress induced learning deficits and is associated with a decrease in granule and CA3 cell dendritic tree size in rat hippocampus. Anatomical Science International. 82(4):211-217.

Huizink, A. C., Robles de Medina, P. G., Mulder, E. J., Visser, G. H., Buitelaar, J. K. (2003). Stress during pregnancy is associated with developmental outcome in infancy. Journal of Child Psychology and Psychiatry 44(6):810-818.

Huttunen, M. O., Niskanen, P. (1978). Prenatal loss of father and psychiatric disorders. Archives of General Psychiatry. 35(4):429-431.

Ishiwata, H., Shiga, T., Okado, N., (2005). Selective serotonin reuptake inhibitor treatment of early postnatal mice reverses their prenatal stress-induced brain dysfunction. Neuroscience 133(4):893-901.

Jacobson, L., Sapolsky, R. (1991). The role of the hippocampus in feedback regulation of the hypothalamic-pituitary-adrenocortical axis. Endocrine Reviews. 12(2):118-34.

Jezova D, Ochedalski T, Glickman M, Kiss A, Aguilera G. (1999). Central corticotropin-releasing hormone receptors modulate hypothalamic-pituitaryadrenocortical and sympathoadrenal activity during stress. Neuroscience. 94(3):797-802.

Joëls, M., Pu, Z., Wiegert, O., Oitzl, M. S., Krugers, H. J. (2006). Learning under stress: how does it work? Trends in Cognitive Sciences 10(4):152-158.

Johansen, J. P., Cain, C. K., Ostroff, L. E., LeDoux, J. E. (2011) Molecular mechanisms of fear learning and memory. Cell. 147(3):509-524.

Johnson, E., Kamilaris, T., Chrousos, G. P., Gold. P. W. (1992). Mechanisms of stress: A dynamic overview of hormonal and behavioural homeostasis. Neuroscience and Biobehavioral Reviews 16(2):115-130.

Kapoor, A., Kostaki, A., Janus, Ch., Matthews, S. G. (2009). The effects of prenatal stress on learning in adult offspring is dependent on the timing of the stressor. Behavioural Brain Research. 197(1):144-149. 
Kastin, A. J., Akerstrom, V. (2002). Differential interactions of urocortin/corticotropin-releasing hormone peptides with the blood-brain barrier. Neuroendocrinology 75(6):367-374.

Keller-Wood, M. E., Dallman, M. F. (1984). Corticosteroid inhibition of ACTH secretion. Endocrine Review. 5(1):1-24.

Kessels, R. P. C., De Haan, E. H. F., Kappele, L. J., Postman, A. (2001). Varieties of human spatial memory : a meta-analysis on the effects of hipocampal lesions. Brain Research Reviews 35(3):295-303.

King, S., Laplante, D. P. (2005). The effects of prenatal maternal stress on children's cognitive development: Project Ice Storm. Stress 8(1):35-45.

King, S., Mancini-Marie, A., Brunet, A., Walker, E., Meaney, M. J., Laplante, D. P. (2009). Prenatal maternal stress from a natural disaster predicts dermatoglyphic asymmetry in humans. Development and Psychopathol. 21(2):343353.

Kinney, D. K. (2001). Prenatal stress and risk for schizophrenia. International Journal of Mental Health 29, 62-72.

Kinney, D. K., Hyman, W., Greetham, C., Tramer, S. (1999). Increased relative risk for schizophrenia and prenatal exposure to a severe tornado. Schizophrenia Research. 36, 45-46.

Kinney, D. K., Miller, A. M., Crowley, D. J., Huang, E., Gerber, E. (2008a). Autism prevalence following prenatal exposure to hurricanes and tropical storms in Louisiana. Journal of Autism and Developmental Disorders. 38(3):481-488.

Kinney, D. K., Munir, K. M., Crowley, D. J., Miller, A. M. (2008b). Prenatal stress and risk for autism. Neuroscience and Biobehavioral Reviews. 32(8):15191532.

Kirschbaum, C., Wolf, O. T., May, M., Wippich, W., Hellhammer, D. H. (1996). Stress-and treatment-induced elevations of cortisol levels associated with impaired declarative memory in healthy adults. Life Sciences. 58(17):1475-1483.

Klauer, K. C., Meiser, T., Naumer, B. (2000). Training propositional reasoning. The Quartely Journal Experimental Psychology A, Human Experimental Psychology. 53(3):868-95.

Koehl, M., Darnaudery, M., Dulluc, J., Van Reeth, O., Le Moal, M., Maccari, S. (1999). Prenatal stress alters circadian activity of hypothalamopituitary-adrenal axis and hippocampal corticosteroid receptors in adult rats of both gender. Journal of Neurobiology. 40(3):302-315. 
Koehl, M., Barbazanges, A., Le Moal, M., Maccari, S. (1997). Prenatal stress induces a phase advance of circadian corticosterone rhythm in adult rats which is prevented by postnatal stress. Brain Research. 759(2):317-320.

Koolhaas, J. M., Bartolomucci, A., Buwalda, B., de Boer, S. F., Flügge, G., Korte, S. M., Meerlo, P., Murison, R., Olivier, B., Palanza, P., Richter-Levin, G., Sgoifo, A., Steimer, T., Stiedl, O., van Dijk, G., Wöhr, M., Fuchs, E. (2011). Stress revisited: a critical evaluation of the stress concept. Neuroscience and Biobehavioral Reviews. 35(5):1291-301.

Kruglikov, R. I., Orlova, N. V., Getsova V. M. (1991). The noradrenaline and serotonin content in symmetrical parts of the normal rat brain and during learning and peptide administration. Zhurnal Vysshei Nervoi Deiatelnosti Imeni IP Pavlova. 41(2): 359-363.

Kupfermann, I. (1991). Functional studies of cotransmission. Physiological Review. 71(3):683-732.

Lafenêtre, P., Leske, O., Ma-Högemeie, Z., Haghikia, A., Bichler, Z., Wahle, P., Heumann, R. (2010). Exercise can rescue recognition memory impairment in a model with reduced adult hippocampal neurogenesis. Frontiers in Behavioral Neuroscience. 34(3):1-9.

Laplante, D. P., Barr, R. G., Brunet, A., Galbaud du Fort, G., Meaney, M. L., Saucier, J. F., Zelazo, P. R., King, S. (2004). Stress during pregnancy affects general intellectual and language functioning in human toddlers. Pediatric Research. 56(3):400-410.

Lee, M. H., Rabe, A. (1999). Infantile handling eliminates reversal learning deficit in rats prenatally exposed to alcohol. Alcohol 18(1):49-53.

Lemaire, V., Koehl, M., Le Moal, M., Abrous, D. N., (2000). Prenatal stress produces learning deficits associated with an inhibition of neurogenesis in the hippocampus. Proceedings of the National Academy of Sciences of the United States of America. 97(20):11032-11037.

Lemaire, V., Lamarque, S., Le Moal, M., Piazza, P. -V., Abrous, D. N. (2006). Postnatal stimulation of the pups counteracts prenatal stress-induced deficits in hippocampal neurogenesis. Biological Psychiatry 59(9):786-792.

Levine, S. (1957). Infantile experience and resistance to physiological stress. Science 126(3270):795-796.

Levine, S., Mullins, R. (1967). Neonatal androgen or estrogen treatment and the adrenal cortica response to stress in adult rats. Endocrinology 80(6):11771179. 
Li, H., Jia, N., Bai, Z., Chen, R., Song, T., Li, X., Cai, Q., Zhu, Z., Liu, J. (2008). NF-KB regulates prenatal stress-induced cognitive impairment in offspring rats. Behavioral Neuroscience 122(2):331-339.

Li, J., Olsen, J., Vestergaard, M., Obel, C. (2010). Attention-deficit/ hyperactivity disorder in the offspring following prenatal maternal bereavement: a nationwide follow-up study in Denmark. European Child and Adolescent Psychiatry 19(10):747-753.

Linnet, K. M., Dalsgaard, S., Obel, C., Wisborg, K., Henriksen, T. B., Rodriguez, A., Kotimaa, A., Moilanen, I., Thomsen, P. H., Olsen, J., Jarvelin, M. R. (2003). Maternal lifestyle factors in pregnancy risk of attention deficit hyperactivity disorder and associated behaviors: review of the current evidence. American Journal of Psychiatry 160(6):1028-1040.

Louvart, H., Maccari, S., Darnaudery, M., (2005). Prenatal stress affects behavioral reactivity to an intense stress in adult female rats. Brain Research. 1031(1):67-73.

Luine, V. N., Spencer, R. L., McEwen, B. S. (1993). Effects of chronic corticosterone ingestion on spatial memory performance and hippocampal serotonergic function. Brain Research. 616(1-2):65-70.

Lupien S. J., Lepage, M. (2001). Stress, memory, and the hippocampus: can't live with it, can't live without it. Behavioural Brain Research. 127(1-2): 137158.

Ma, S., Morilak, D. A. (2005). Norepinephrine release in medial amygdala facilitates activation of the hypothalamic-pituitary-adrenal axis in response to acute immobilisation stress. Journal of Neuroendocrinology. 17(1):22-28.

Maccari, S., Morley-Fletchera, S. (2007). Effects of prenatal restraint stress on the hypothalamus-pituitary-adrenal axis and related behavioural and neurobiological alterations. Psychoneuroendocrinology 32 Supplement 1:S10-S15.

Maccari, S., Piazza, P. V., Kabbaj, M., Barbazanges, A., Simon, H., Le Moal, M. (1995). Adoption reverses the long-term impairment in glucocorticoid feedback induced by prenatal stress. Journal of Neuroscience. 15(1 pt 1):110-116.

MacDonald, J. F., Jackson, M. F., Beazely, M. A. (2006). Hippocampal long-term synaptic plasticity and signal amplification of NMDA receptors. Critical Reviews in Neurobiology. 18(1-2):71-84.

Maier, S. F., Seligman, M. E. P. (1976). Learned helplessness - theory and evidence. Journal Experimental Psychology. 105, 3-46.

Maier, S. F., Watkins, L. R. (2005). Stressor controllability and learned helplessness: the roles of the dorsal raphe nucleus, serotonin, and corticotropinreleasing factor. Neuroscience and Biobehavioral Reviews. 29(4-5):829-841. 
Martin, K. C., Casadio, A., Zhu, H., Yaping, E., Rose, J. C., Chen, M., Bailey, C. H., Kandel, E. R. (1997). Synapse-specific, long-term facilitation of aplysia sensory to motor synapses: a function for local protein synthesis in memory storage. Cell. 91(7):927-38.

McDonald, R. J., White, N. M. (1994). Parallel information processing in the water maze: evidence for independent memory systems involving dorsal striatum and hippocampus. Behavioral and Neural Biology. 61(3):260-70.

McGaugh, J. L., Cahill, L. (1997). Interaction of neuromodulatory systems in modulating memory storage. Behavioral Brain Research. 83(1-2):31-38.

McEwen, B. S. (2000). Effects of adverse experiences for brain structure and function. Biological Psychiatry 48(8):721-731.

McEwen, B.S., Alves, S.E., Bulloch, K., Weiland, N.G. (1997). Ovarian steroids and the brain: implications for cognition and aging. Neurology 48(5 Suppl 7):S8-15.

McEwen, B. S., Lieberburg, I., Chaptal, C., Krey, L. C. (1977). Aromatization: important for sexual differentiation of the neonatal rat brain. Hormones and Behavior. 9(3):249-263.

McEwen, B. S., Sapolsky, R. M. (1995). Stress and cognitive function. Current Opinion in Neurobiology. 5(2):205-216

McEwen, B. S., Weiss, J., Schwartz, L. (1968). Selective retention of corticosterone by limbic structures in rat brain. Nature 220(5170): 911-912.

McEwen, B., S. (1998). Stress, adaptation, and disease. Allostasis and allostatic load. Annals of the New York Academy of Sciences. 840:33-44.

McIntosh, D. E., Mulkins, R. S., Dean, R. S. (1995). Utilization of maternal perinatal risk indicators in the differential diagnosis of ADHD and UADD children. Int. Journal of Neuroscience. 81(1-2):35-46.

Meaney, M., Aitiken, D. (1985). The effects of early postnatal handling on hippocampal glucocorticoid receptor concentrations: Temporal parameters. Brain Research. 354(2):301-304.

Meaney, M. J., Aitiken, D. H., Bodnoff, S. R., Iny, L. J., Tatarevicz, J. E., Sapolsky, R. M. (1985). Early postnatal handling alters glucocorticoid receptor concentrations in selected brain regions. Behavioral Neuroscience. 99(4): 765-770.

Meaney, M. J., Aitken, D. H., Viau, V., Sharma, S., Sarrieau, A. (1989). Neonatal handling alters adrenocortical negative feedback sensitivity and hippocampal glucocorticoid receptor binding in the rat. Neuroendocrinology, 50(5):597-604. 
Meaney, M. J., Diorio, J., Francis, D., LaRocque, S., O'Donnell, D., Smythe, J. W., Sharma, S., Tannenbaum, B. (1994). Environmental regulation of the development of glucocorticoid receptor systems in the rat forebrain. The role of serotonin. Annals of the New York Academy Sciences. 746:260-273.

Meerlo, P., Horvath, K. M., Nagy, G. M., Bohus, B., Koolhaas, J. M. (1999). The influence of postnatal handling on adult neuroendocrine and behavioural stress reactivity. Journal of Neuroendocrinology, 11(12): 925-933.

Mineka, S., Hendersen, R. W. (1985). Controllability and predictability in acquired motivation. Annual Review of Psychology 36: 495-529.

Moguilewsky, M., Raynaud, J. P. (1980). Evidence for a specific mineralocorticoid receptor in rat pituitary and brain. Journal of Steroid Biochemistry 12:309-314.

Morgado, I. (2005). Psicobiología del aprendizaje y la memoria: fundamentos y avances recientes. Revista de Neurologia. 40(5):289-297.

Morley-Fletcher, S., Darnaudery, M., Koehl, M., Casolini, P., Van Reeth, O., Maccari, S., (2003a). Prenatal stress in rats predicts immobility behavior in the forced swim test. Effects of a chronic treatment with tianeptine. Brain Research. 989(2):246-251.

Morley-Fletcher, S., Rea, M., Maccari, S., Laviola, G., (2003b). Environmental enrichment during adolescence reverses the effects of prenatal stress on play behaviour and HPA axis reactivity in rats. The European Journal Neuroscience. 18(12): 3367-3374.

Moscovitch, M., Nadel, L., Winocur, G., Gilboa, A., Rosenbaum, R. S. (2006). The cognitive neuroscience of remote episodic, semantic and spatial memory. Current Opinion in Neurobiology. 16(2):179-190.

822.

Muller, R. U. (1996). A quarter of a century of place cells. Neuron. 17:813-

Nakamura, T., Keep, R. F., Hua, Y., Park, J. W., Itano, T., Nagao, S., Hoff, J. T., Xi, G. H. (2005). Intracerebral hemorrhage induces edema and oxidative stress and alters $\mathrm{N}$-methyl-D-aspartate receptor subunits expression. Acta Neurochirurgica Supplementum. 95, 421-424.

Natelson, B. H., Ottenweller, J. E., Cook, J. A., Pitman, D. L., McCarty, R., Tapp. W.N. (1988). Effect of stress intensity on habituation of the adrenocortical stress response. Physiology and Behavior, 43(1):41-46.

Nauta, W. J., Feirtag, M. (1979). The organization of the brain. Scientific American. 241(3):88-111. 
Nelson, D. L., Schreiber, T. A., McEvoy, C. L. (1992). Processing implicit and explicit representations. Psychological Review. 99(2): 322-348.

Neves, S. R., Tsokas, P., Sarkar, A., Grace, E. A., Rangamani, P., Taubenfeld, S. M., Alberini, C. M., Schaff, J. C., Blitzer, R. D., Moraru, I. I., Iyengar, R. (2008). Cell shape and negative links in regulatory motifs together control spatial information flow in signaling networks. Cell. 133(4):666-80.

Nishio, H., Kasuga, S., Ushijima, M., Harada, Y. (2001). Prenatal stress and postnatal development of neonatal rats-sex-dependent effects on emotional behavior and learning ability of neonatal rats. International Journal of Developmental Neuroscience. 19(1):37-45.

Nunez, J. F., Ferre, P., Garcia, E., Escorihuela, R. M., Fernandez-Teruel, A., Tobena, A. (1995). Postnatal handling reduces emotionality ratings and accelerates two-way active avoidance in female rats. Physiology and Behavior 57(5):831-835.

Nunez, J. F., Ferre, P., Escorihuela, R. M., Tobena, A., Fernandez-Teruel, A. (1996). Effects of postnatal handling of rats on emotional, HPA-axis, and prolactin reactivity to novelty and conflict. Physiology and Behavior 60(5):13551359.

O'Keefe, J., Dostrovsky, J. (1971). The hippocampus as a spatial map. Preliminary evidence from unit activity in the freely moving rat. Brian Research 34(1):171-175.

Packard, M. G., Hirsh, R., White, N. M. (1989). Differential effects of fornix and caudate nucleus lesions on two radial maze tasks: evidence for multiple memory systems. The Journal of Neuroscience. 9(5):1465-1472.

Packard, M. G., Knowlton, B. J. (2002). Learning and memory functions of the Basal Ganglia. Annual Review of Neuroscience. 25:563-93.

Packard M. G., McGaugh J. L. (1996). Inactivation of hippocampus or caudate nucleus with lidocaine differentially affects expression of place and response learning. Neurobiology of Learning and Memory. 65(1):65-72.

Packard, M. G. McGaugh J. L. (1992). Double dissociation of fornix and caudate nucleus lesions on acquisition of two water maze tasks: further evidence for multiple memory systems. Behavioral Neuroscience. 106(3):439-46.

Pecoraro, N., Gomez, F., La Fleur, S., Roy, M., Dallman, M. F. (2005). Single, but not multiple pairings of sucrose and corticosterone enhance memory for sucrose drinking and amplify remote reward relativity effects. Neurobiology of Learning and Memory 83(3):188-195.

Pinnock, S. B., Herbert, J. (2001). Corticosterone differentially modulates expression of corticotropin releasing factor and arginine vasopressin mRNA in the 
hypothalamic paraventricular nucleus following either acute or repeated restraint stress. European Journal of Neuroscience 13(3): 576-584.

Pitman, D. L., Ottenweller, J. E., Natelson, B. H. (1988). Plasma corticosterone levels during repeated presentation of two intensities of restraint stress: Chronic stress and habituation. Physiology and Behavior. 43(1):47-56.

Plotsky, P. M., Thrivikraman, K. V., Nemeroff, C. B., Caldji, C., Sharma, S., Meaney, M. J. (2005). Long-term consequences of neonatal rearing on central corticotropin-releasing factor systems in adult male rat offspring. Neuropsychopharmacology. 30(12):2192-2204.

Poltyrev, T., Keshet, G.I., Kay, G., Weinstock, M., (1996). Role of experimental conditions in determining differences in exploratory behavior of prenatally stressed rats. Developmental Psychobiology. 29(5):453-462.

Prado-Alcala, R. A., Quirarte, G. L. (2007). [The consolidation of memory, one century on]. Revista de Neurolgia. 45(5):284-292.

Pryce, C. R., Bettschen, D., Feldon, J. (2001). Comparison of the effects of early handling and early deprivation on maternal care in the rat. Developmental Psychobiology. 38(4):239-51.

Retana-Márquez, S., Bonilla-Jaime, H., Vázquez-Palacios, G., DomínguezSalazar, E., Martínez-García, J., Velázquez-Moctezuma, J. (2003). Body weight gain and diurnal differences of corticosterone changes in response to acute and chronic stress in rats. Psychoneuroendocrinology 28(2):207-227.

Reul, J., de Kloet, E. (1985). Tow receptor systems of corticosterone in rat brain : Microdistribution and differential occupation. Endocrinology 177(6):25052511.

Rigter, J., Veldhuis, H., DeKloet, E. (1984). Spatial orientation and the hippocampal corticosterone receptor system of old rats; Effect of ACTH 4-9 analogue ORC2766. Brain Research. 309(2):393-398.

Rivier, C., Vale, W. (1983). Modulation of stress-induced ACTH release by CRF, catecholamines, and vasopressin. Nature 305(5932): 325-327.

Rodriguez, A., Bohlin, G. (2005). Are maternal smoking and stress during pregnancy related to ADHD symptoms in children? Journal of Child Psychology and Psychiatry 46(3):246-254.

Rodríguez Moreno A. (2003). Receptores de kainato. Función en la regulación de la transmisión sináptica gabérgica en el hipocampo. Revista de Neurología. 36(9):852-859

Rohde, W., Ohkawa, T., Dobashi, K., Arai, K., Okinaga, S., Dörner, G. (1983). Acute effects of maternal stress on fetal blood catecholamines and 
hypothalamic LH-RH content. Experimental and Clinical Endocrinology 82(3):268274.

Roozendaal, B. (2002). Stress and memory: opposing effects of glucocorticoids on memory consolidation and memory retrieval. Neurobiology of Learning and Memory 78(3):578-595.

Roozendaal, B. (2003). Systems mediating acute glucocorticoid effects on memory consolidation and retrieval. Progress in Neuro-Psychopharmacology and Biological Psychiatry 27(8):1213-1223.

Sandi, C. (1998). The role and mechanisms of action of glucocorticoid involvement in memory storage. Neural Plasticity 6(3):41-52.

Sandi, C., Pinelo-Nava, M. T. (2007). Stress and memory: Behavioral effects and neurobiological mechanisms. Neural Plasticity 2007:78970

Sandi, C. Loscertales, M. (1999). Opposite effects on NCAM expression in the rat frontal cortex induced by acute vs. chronic corticosterone treatments. Brain Research. 828(1-2):127-134.

Santín, L. J., Rubio, S., Begega, A., Miranda, R., Arias, J. L. (2000). Aprendizaje espacial e hipocampo. Revista de Neurología. 31:455-462.

Sapolsky, R. (1985). Glucorticoid toxicity in the hippocampus: Temporal aspects of neuronal vulnerability. Brain Research. 359(1-2):300-305.

Sapolsky, R. M. (1992). Stress, the Aging Brain, and the Mechanisms of Neuron Death (MIT Press, Cambridge, Massachusetts).

Sapolsky, R., Krey, L. C., McEwen, B. (1983a). Corticosterone receptors decline in a site-specific manner in the aged rat brain. Brain Research. 289(1):235240.

Sapolsky, R., Krey, L. C., McEwen, B. (1983b). The adrenocortical stressresponse in the aged male rat: Impairment of recovery from stress. Experimental Gerontology. 18(1):55-63.

Sapolsky, R. M., Krey, L. C., McEwen, B. S. (1984). Stress down-regulates corticosterone receptors in a site-specific manner in the brain. Endocrinology. 114(1):287-92.

Sapolsky, R., Krey, L. C., McEwen, B. S. (1986). The neuroendocrinology of stress and angig: The glucocorticoid cascade hypothesis. Endocrinology Review. 7(3): 284-301.

Sapolsky, R., Pulsinelli, W. (1985). Glucocorticoids potentiate ischemic injury to neurons: Terapeutic implications. Science 229(4720):1397-1399. 
Schafer, M. Stein, C. (1998). The sympathetic nervous system and pain. Anaesthesist. 47(1):2-3.

Schapiro, S., Vukovich, K. R. (1970). Early experience effects upon cortical dendrites: a proposed model for development. Science 167(916):292-294.

Scoville, W. B., Milner, B. (1957). Loss of recent memory after bilateral hippocampal lesions. Journal of Neurology, Neurosurgery, and Psychiatry 20(1):11-21.

Shen, J., Barnes, C. A., McNaughton, B. L., Skaggs, W. E., Weaver, K. L. (1997). The effect of aging on experience-dependent plasticity of hippocampal place cells. Journal of Neuroscience. 17:6769-6782. 11(2):137-144.

Shors, T. J. (2004). Learning during stressful times," Learning \& Memory

Shors, T. J. (2006). Stressful experience and learning across the lifespan. Annual Review of Psychology. 57, 55-85.

Shors, T. J., Seib, T. B., Levine, S., Thompson, R. F. (1989). Inescapable versus escapable shock modulates long-term potentiation in the rat hippocampus. Science 244(4901):224-226.

Siiteri, P. K., Murai, J. T., Hammond, G. L., Nisker, J. A., Raymoure, W. J., Kuhn, R. W. (1982). The serum transport of steroid hormones. Recent Progress in Hormone Research. 38, 457-510.

Son, G. H., Geum, D., Chung, S., Kim, E. J., Jo, J. H., Kim, C. M., Lee, K. H., Kim, H., Choi, S., Kim, H. T., Lee, C. J., Kim, K. (2006). Maternal stress produces learning deficits associated with impairment of NMDA receptor- mediated synaptic plasticity. Journal of Neuroscience. 26(12):3309-3318.

Sousa, N., Lukoyanov, N. V., Madeira, M. D., Almeida, O. F., PaulaBarbosa, M. M. (2000). Reorganization of the morphology of hippocampal neurites and synapses after stress-induced damage correlates with behavioral improvement. Neuroscience 97(2):253-266.

Squire, L. R., Zola-Morgan, S. (1991). The medial temporal lobe memory system. Science 253(5026):1380-1386.

Stamatakis, A., Pondiki S., Kitraki, E., Diamantopoulou, A., Panagiotaropoulos, T., Raftogianni, A., Stylianopoulou, F. (2008). Effect of neonatal handling on adult rat spatial learning and memory following acute stress. Stress. 11(2):148-159

Steimer, T., Escorihuela, R. M., Fernandez-Teruel, A., Driscoll, P. (1998). Long-term behavioural and neuroendocrine changes in Roman high (RHA/Verh)- 
and low (RLA-Verh)-avoidance rats following neonatal handling. International Journal of Developmental Neuroscience. 16(3-4):165-174.

Stanford, S. C., Salmon, P. (1993). Decoding the neurochemical basis of resistance to stress: a reply. Journal of Psychopharmacology. 7(1 Suppl):89-90.

Sterling and Eyer (Fisher S., Reason J. (eds): Handbook of Life Stress, Cognition and Health. J. Wiley Ltd. 1988, p. 631)

Takahashi, L. K., Turner, J. G., Kalin, N. H. (1992). Prenatal stress alters brain catecholaminergic activity and potentiates stress-induced behavior in adult rats. Brain Research. 574(1-2):131-137.

Takahashi, L. K., Turner, J. G., Kalin, N. H. (1998). Prolonged stressinduced elevation in plasma corticosterone during pregnancy in the rat: implications for prenatal stress studies. Psychoneuroendocrinology 23(6):571-581.

Talge, N. M., Neal, C., Glover, V. (2007). Antenatal maternal stress and long-term effects on child neurodevelopment: how and why? Journal of Child Psychology and Psychiatry 48(3-4):245-261.

Tanapat, P., Hastings, N. B., Reeves, A. J., Gould, E. (1999). Estrogen stimulates a transient increase in the number of new neurons in the dentate gyrus of the adult female rat. Journal of Neuroscience. 19(14):792-801.

Tang, A. C. (2001). Neonatal exposure to novel environment enhances hippocampal-dependent memory function during infancy and adulthood. Learn and Memory. 8(5):257-264.

Tang, A. C., Akers, K. G., Reeb, B. C., Romeo, R. D., McEwen, B. S. (2006). Programming social, cognitive, and neuroendocrine development by early exposure to novelty. Proceedings of the National Academy of Sciences of the United States of America. 103(42):15716-15721.

Tang, A. C., Zou, B. (2002). Neonatal exposure to novelty enhances longterm potentiation in CA1 of the rat hippocampus. Hippocampus. 12(3):398-404.

Thompson, W. R., (1957). Influence of prenatal maternal anxiety on emotionality in young rats. Science 125(3250):698-699.

Tilders, F. J. H., Barkenbosch, F. (1986). CRF and catecholamines; Their place in the central and peripheral regulation of the stress response. Acta Endocrinologica Supplementum. (Copenh.) 276, 63-75.

Valdez-Santiago, R., Sanin-Aguirre, L. H. (1996). Domestic violence during pregnancy and its relationship with birth weight. Public Health of Mexico. 38(5):352-362.

Vallée, M., Maccari, S., Dellu, F., Simon, H., Le Moal, M., Mayo, W. (1999). Long-term effects of prenatal stress and postnatal handling on age-related 
glucocorticoid secretion and cognitive performance: a longitudinal study in the rat. The European Journal of Neuroscience. 11(8):2906-2916.

Vallée, M., Mayo, W., Dellu, F., Le Moal, M., Simon, H., Maccari, S. (1997). Prenatal stress induces high anxiety and postnatal handling induces low anxiety in adult offspring: correlation with stress-induced corticosterone secretion. Journal of Neuroscience. 17(7):2626-2636.

Van den Hove, D. L., Steinbusch, H. W., Bruschettini, M., Gazzolo, D., Frulio, R., Scheepens, A., Prickaerts, J., Blanco, C. E. (2006). Prenatal stress reduces S100B in the neonatal rat hippocampus. Neuroreport. 17(10):1077-1080.

Van Os, J., Selten, J. P. (1998). Prenatal exposure to maternal stress and subsequent schizophrenia. The invasion of The Netherlands. The British Journal of Psychiatry 172, 324-326.

Van Waes, V., Enache, M., Dutriez, I., Lesage, J., Morley-Fletcher, S., Vinner, E., Lhermitte, M., Vieau, D., Maccari, S., Darnaudery, M., (2006). Hyporesponse of the hypothalamic-pituitaryadrenocortical axis after an ethanol challenge in prenatally stressed adolescent male rats. The European Journal of Neuroscience. 24(4):1193-1200.

Verfaellie, M. Keane, M. M. (1997). The neural basis of aware and unaware forms of memory. Seminars in Neurology. 17(2):153-161.

Viau, V., Sharma, S., Plotsky, P. M., Meaney, M. J. (1993). Increased plasma ACTH responses to stress in nonhandled compared with handled rats require basal levels of corticosterone and are associated with increased levels of ACTH secretagogues in the median eminence. Journal of Neuroscience. 13(3):1097-105.

Vicens, P., Redolat, R., Carrasco, M. C. (2003). Aprendizaje especial y laberinto de agua: Metodología y aplicaciones. Psicothema 4(15):539-544.

Villescas, R., Bell, R. W., Wright, L., Kufner, M. (1977). Effect of handling on maternal behavior following return of pups to the nest. Devevelopmental Psychobiology. 10(4):323-329.

Viltart, O., Mairesse, J., Darnaudery, M., Louvart, H., Vanbesien-Mailliot, C., Catalani, A., Maccari, S. (2006). Prenatal stress alters Fos protein expression in hippocampus and locus coeruleus stress-related brain structures. Psychoneuroendocrinology 31(6):769-780.

Wadhwa, P. D., Sandman, C. A., Garite, T. J. (2001). The neurobiology of stress in human pregnancy: implications for prematurity and development of the fetal central nervous system. Progress in Brain Research. 133:131-142. 
Wakshlak, A., Weinstock, M., (1990). Neonatal handling reverses behavioral abnormalities induced in rats by prenatal stress. Physiology and Behavior. 48(2):289-292.

Walf, A. A., Frye, C. A. (2007). Estradiol decreases anxiety behavior and enhances inhibitory avoidance and gestational stress produces opposite effects. Stress. 10(3):251-260.

Wang, R. F., Spelke, E. (2002). Human spatial representation: insights from animals. Trends in Cognitive Neuroscience. 6:376-382.

Ward, I. L., Weisz, J. (1984). Differential effects of maternal stress on circulating levels of corticosterone, progesterone, and testosterone in male and female rat fetuses and their mothers. Endocrinology 114(5):1635-1644.

Watson, J. B., Mednick, S. A., Huttunen, M., Wang, X. (1999). Prenatal teratogens and the development of adult mental illness. Developmental Psychopathology. 11(3):457-66.

Weinstock, M. (2007). Gender differences in the effects of prenatal stress on brain development and behaviour. Neurochemical Research. 32(10):1730-1740.

Weinstock, M., Fride, E., Hertzberg, R. (1988). Prenatal stress effects on functional development of the offspring. Progress in Brain Research. 73, 319-331.

Wood, E. R., Dudchenko, P. A., Eichenbaum, H. (2001). Cellular correlates of behavior. International Review Neurobiology. 45, 293-312.

Woods, S. M., Melville, J. L., Guo, Y., Fan, M. Y., Gavin, A. (2010). Psychosocialstress during pregnancy. American Journal of Obstetrics and Gynecology 202(1): 61.e1-7.

Wu, J. ; Song, T. B. ; Li, Y. J. ; He, K. S. ; Ge, L. ; Wang, L. R. (2007). Prenatal restraint stress impair learning and memory and hippocampal PKCbeta 1 expression and translocation in offspring rats. Brain Research. (1141): 205-213.

Xu, L., Anwyl, R., Rowan, M. J. (1997). Behavioural stress facilitates the induction of long-term depression in the hippocampus. Nature 387(6632):497-500.

Yaka, R., Salomon, S., Matzner, H., Weinstock, M. (2007). Effect of varied gestational stress on acquisition of spatial memory, hippocampal LTP and synaptic proteins in juvenile male rats. Behavioral and Brain Research. 179(1):126-132.

Yang, J., Han, H., Cao, J., Li, L., Xu, L. (2006). Prenatal stress modifies hippocampal synaptic plasticity and spatial learning in young rat offspring. Hippocampus 16(5):431-436.

Yates, C. M., Simpson, J., Russell, D., Gordon, A. (1980). Cholinergic enzymes in neurofibrillary degeneration produced by aluminium. Brain Research. 197(1):269-274. 
Zager, E. L., Black, P. M. (1985). Neuropeptides in human memory and learning processes. Neurosurgery. 17(2):355-369.

Zagron, G., Weinstock, M. (2006). Maternal adrenal hormone secretion mediates behavioural alterations induced by prenatal stress in male and female rats. Behavioral and Brain Research. 175(2):323-328. 